NCCN

\section{Prostate Cancer Early Detection, Version 2.2015}

\section{Clinical Practice Guidelines in Oncology}

Peter R. Carroll, MD, MPH; J. Kellogg Parsons, MD, MHS;

Gerald Andriole, MD; Robert R. Bahnson, MD;

Daniel A. Barocas, MD, MPH; Erik P. Castle, MD;

William J. Catalona, MD; Douglas M. Dahl, MD;

John W. Davis, MD; Jonathan I. Epstein, MD;

Ruth B. Etzioni, PhD; Thomas Farrington, BSEE;

George P. Hemstreet III, MD, PhD; Mark H. Kawachi, MD;

Paul H. Lange, MD; Kevin R. Loughlin, MD;
William Lowrance, MD, MPH; Paul Maroni, MD

James Mohler, MD; Todd M. Morgan, MD;

Robert B. Nadler, MD; Michael Poch, MD;

Chuck Scales, MD; Terrence M. Shaneyfelt, MD, MPH;

Marc C. Smaldone, MD, MSHP; Geoffrey Sonn, MD;

Preston Sprenke, MD; Andrew J. Vickers, PhD;

Robert Wake, MD; Dorothy A. Shead, MS; and

Deborah Freedman-Cass, PhD

\section{Introduction}

Prostate cancer represents a spectrum of disease that ranges from nonaggressive, slow-growing disease that may not require treatment to aggressive, fast-growing disease that does. The NCCN Clinical Practice Guidelines in Oncology (NCCN Guidelines) for Prostate Cancer Early Detection provide a set of sequential recommendations detailing a screening and

\begin{abstract}
Prostate cancer represents a spectrum of disease that ranges from nonaggressive, slow-growing disease that may not require treatment to aggressive, fast-growing disease that does. The NCCN Guidelines for Prostate Cancer Early Detection provide a set of sequential recommendations detailing a screening and evaluation strategy for maximizing the detection of prostate cancer that is potentially curable and that, if left undetected, represents a risk to the patient. The guidelines were developed for healthy men who have elected to participate in the early detection of prostate cancer, and they focus on minimizing unnecessary procedures and limiting the detection of indolent disease. (J Natl Compr Canc Netw 2015;13:1534-1561)
\end{abstract}

\section{NCCN Categories of Evidence and Consensus}

Category 1: Based upon high-level evidence, there is uniform NCCN consensus that the intervention is appropriate.

Category 2A: Based upon lower-level evidence, there is uniform NCCN consensus that the intervention is appropriate.

Category 2B: Based upon lower-level evidence, there is NCCN consensus that the intervention is appropriate.

Category 3: Based upon any level of evidence, there is major NCCN disagreement that the intervention is appropriate.

\section{All recommendations are category $2 \mathrm{~A}$ unless otherwise noted.}

Clinical trials: NCCN believes that the best management for any cancer patient is in a clinical trial. Participation in clinical trials is especially encouraged.

\section{Please Note}

The NCCN Clinical Practice Guidelines in Oncology (NCCN Guidelines ${ }^{\circledR}$ ) are a statement of consensus of the authors regarding their views of currently accepted approaches to treatment. Any clinician seeking to apply or consult the NCCN Guidelines ${ }^{\circledR}$ is expected to use independent medical judgment in the context of individual clinical circumstances to determine any patient's care or treatment. The National Comprehensive Cancer Network $^{\circledR}\left(\mathrm{NCCN}^{\circledR}\right)$ makes no representation or warranties of any kind regarding their content, use, or application and disclaims any responsibility for their applications or use in any way.

(c) National Comprehensive Cancer Network, Inc. 2015, All rights reserved. The NCCN Guidelines and the illustrations herein may not be reproduced in any form without the express written permission of NCCN.

\section{Disclosures for the NCCN Prostate Cancer Early Detection Panel}

At the beginning of each NCCN Guidelines panel meeting, panel members review all potential conflicts of interest. NCCN, in keeping with its commitment to public transparency, publishes these disclosures for panel members, staff, and NCCN itself.

Individual disclosures for the NCCN Prostate Cancer Early Detection Panel members can be found on page 1561. (The most recent version of these guidelines and accompanying disclosures are available on the NCCN Web site at NCCN.org.)

These guidelines are also available on the Internet. For the latest update, visit NCCN.org. 


\section{Journal of the National Comprehensive Cancer Network}

evaluation strategy for maximizing the detection of prostate cancer that is potentially curable and that, if left undetected, represents a risk to the patient.

These guidelines focus on minimizing unnecessary procedures and limiting the detection of indolent disease. These guidelines were developed for men who have elected to participate in the early detection of prostate cancer. The panel does not support unselected and uninformed population-based screening. The panel supports screening only in healthy men. Any clinician who uses these guidelines is expected to exercise independent medical judgment in the context of individual clinical circumstances, and to fully incorporate patient preferences in deciding how to apply these guidelines.

\section{Overview}

Prostate cancer is the most commonly diagnosed cancer and the second leading cause of cancer deaths in American men. In 2015, it is estimated that 220,800 men will be diagnosed with prostate cancer and 27,540 will die of this disease. ${ }^{1}$ During the same period, nearly 20 million men in the United States will be confronted with important decisions regarding early detection for prostate cancer. Men in the United States have about 1 chance in 7 of eventually being diagnosed with this malignancy and about 1 chance in 30 of eventually dying of it. ${ }^{2}$

By 2015, death rates for prostate cancer in the United States had fallen 47\% from peak rates, largely due to early detection and improved treatment. ${ }^{1}$ The panel supports the continued use of prostate-specif-

Text cont. on page 1540 .

\section{NCCN Prostate Cancer Early Detection Panel}

\section{Members}

*Peter R. Carroll, MD, MPH/Chair $\omega$

UCSF Helen Diller Family Comprehensive Cancer Center

*J. Kellogg Parsons, MD, MHS/Vice-Chairף

UC San Diego Moores Cancer Center

Gerald Andriole, MD $\omega$

Siteman Cancer Center at Barnes-Jewish Hospital and

Washington University School of Medicine

Robert R. Bahnson, MDw

The Ohio State University Comprehensive Cancer Center James Cancer Hospital and Solove Research Institute

Daniel A. Barocas, MD, MPHף

Vanderbilt-Ingram Cancer Center

Erik P. Castle, MD $\omega$

Mayo Clinic Cancer Center

William J. Catalona, MD $\omega$

Robert H. Lurie Comprehensive Cancer Center of Northwestern University

Douglas M. Dahl, MD $\omega$

Massachusetts General Hospital Cancer Center

John W. Davis, MD $\omega$

The University of Texas MD Anderson Cancer Center

Jonathan I. Epstein, MD $\neq$

The Sidney Kimmel Comprehensive Cancer Center at Johns Hopkins

Ruth B. Etzioni, PhD\&

Fred Hutchinson Cancer Research Center/

Seattle Cancer Care Alliance

Thomas Farrington, BSEE $¥$

Prostate Health Education Network

George P. Hemstreet III, MD, PhD $\omega$

Fred \& Pamela Buffett Cancer Center

Mark H. Kawachi, MDw

City of Hope Comprehensive Cancer Center

Paul H. Lange, MDw

University of Washington Medical Center/

Seattle Cancer Care Alliance
Kevin R. Loughlin, MDף

Dana-Farber/Brigham and Women's Cancer Center

William Lowrance, MD, MPH $\omega$

Huntsman Cancer Institute at the University of Utah

Paul Maroni, MD $\omega$

University of Colorado Cancer Center

James Mohler, MD $\omega$

Roswell Park Cancer Institute

Todd M. Morgan, MD $\omega$ University of Michigan Comprehensive Cancer Center

Robert B. Nadler, MD $\omega$

Robert H. Lurie Comprehensive Cancer Center of

Northwestern University

Michael Poch, MD $\omega$

Moffitt Cancer Center

Chuck Scales, MD $\omega$

Duke Cancer Institute

Terrence M. Shaneyfelt, MD, MPHP

University of Alabama at Birmingham

Comprehensive Cancer Center

Marc C. Smaldone, MD, MSHP $\omega$

Fox Chase Cancer Center

Geoffrey Sonn, MD $\omega$

Stanford Cancer Center

Preston Sprenke, MD $\omega$

Yale Cancer Center/Smilow Cancer Hospital

Andrew J. Vickers, PhD††

Memorial Sloan Kettering Cancer Center

Robert Wake, MD $\omega$

St. Jude Children's Research Hospital/

The University of Tennessee Health Science Center

NCCN Staff: Dorothy A. Shead, MS, and

Deborah Freedman-Cass, PhD

KEY:

*Writing Committee Member

Specialties: §Radiotherapy/Radiation Oncology; ๆSurgery/ Surgical Oncology; $\omega$ Urology; PInternal Medicine; $\neq$ Pathology; \&Epidemiology; ††Biostatistician; ¥Patient Advocacy 
INTRODUCTION

The panel recognizes that prostate cancer represents a true spectrum of disease and that not all men diagnosed with prostate cancer require treatment. The panel believes that maximizing the detection of early prostate cancer will increase the detection of both indolent (slower-growing) and aggressive (faster-growing) prostate cancers. The challenge is to minimize immediate treatment (over-treatment) of indolent cancers by accurately characterizing the biology of the detected cancer. Identification and selective treatment of aggressive cancers should result in significant decreases in morbidity and mortality while limiting adverse effects on quality of life. The NCCN Guidelines for Prostate Cancer Early Detection do not address the treatment of prostate cancer. See the NCCN Guidelines for Prostate Cancer for prostate cancer treatment recommendations (to view the most recent verstion, visit NCCN.org). It is the intention of the panel that these guidelines be linked and, specifically, early detection strategies that do not recognize the importance of refined and selective treatment may result in harm.

The guidelines are specifically for men opting to participate in an early detection program (after receiving the appropriate counseling on the pros and cons). It is the majority opinion of the NCCN Prostate Cancer Early Detection Panel Members that there is a growing population of men currently being diagnosed with prostate cancer who can, and should, be monitored for their disease as presented in the NCCN Guidelines for Prostate Cancer (available at NCCN.org). The guidelines for when to start and stop screening, at what intervals to conduct screening, and when to biopsy were recommended by most panel members, but a consensus was not reached. The guidelines are continuously in a state of evolution, and the panel will incorporate changes based on new evidence and expert opinion and provide a rating of consensus for each recommendation. 


\section{Prostate Cancer Early Detection, Version 2.2015}

BASELINE EVALUATION
EARLY DETECTION EVALUATION

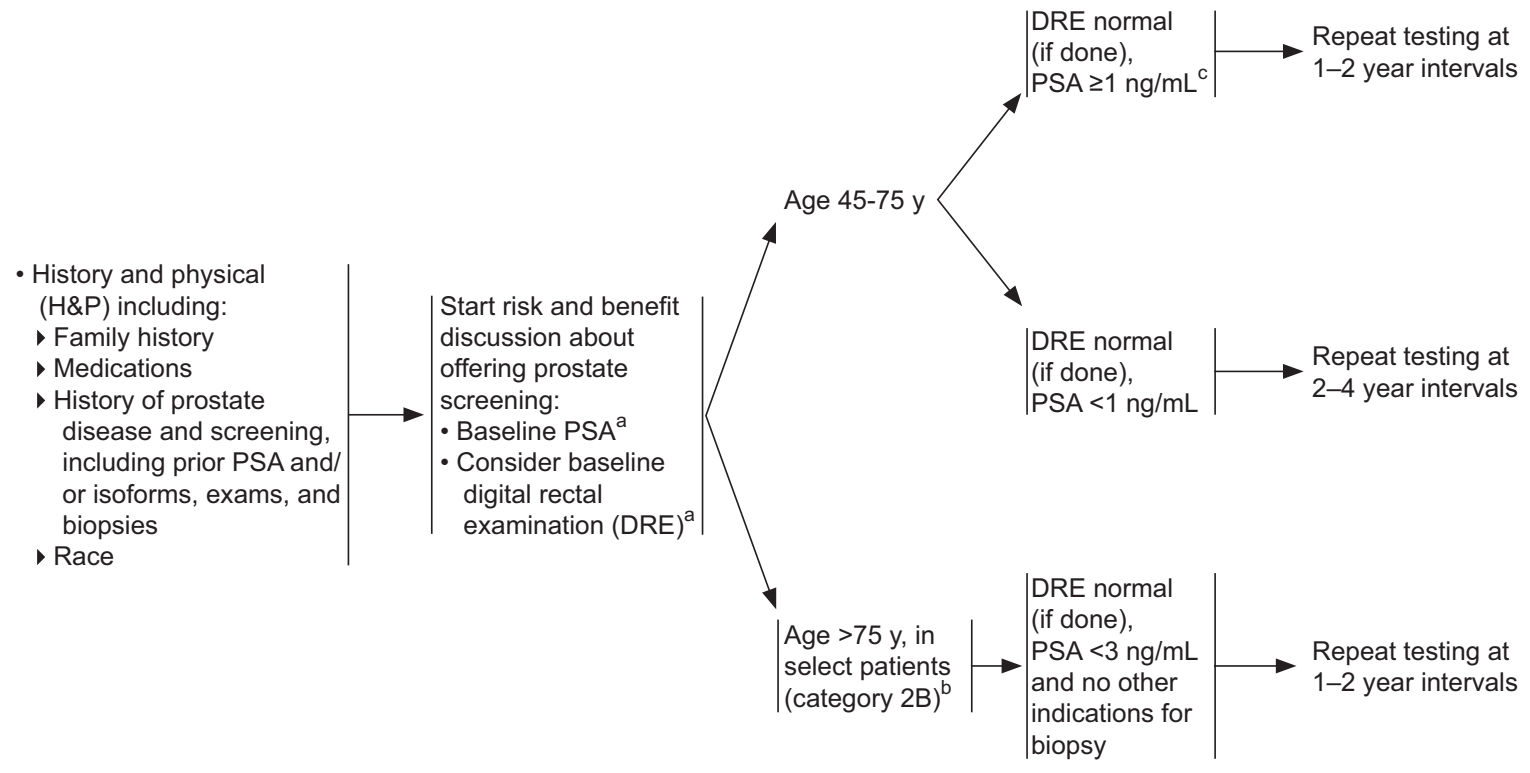

${ }^{a}$ The best evidence supports the use of serum PSA for the early detection of prostate cancer. DRE should not be used as a stand-alone test, but should be performed in those with an elevated serum PSA. DRE may be considered as a baseline test in all patients as it may identify high-risk cancers associated with "normal" serum PSA values. Medications such as $5 a$-reductase inhibitors (finasteride and dutasteride) are known to decrease PSA by approximately $50 \%$, and PSA values in these men should be corrected accordingly.

${ }^{b}$ Testing above the age of 75 years of age should be done with caution and only in very healthy men with little or no comorbidity as a large proportion may harbor cancer that would be unlikely to affect their life expectancy, and screening in this population would substantially increase rates of over-detection. However, a clinically significant number of men in this age group may present with high-risk cancers that pose a significant risk if left undetected until signs or symptoms develop. One could consider increasing the PSA threshold for biopsy in this group (ie, $>4 \mathrm{ng} / \mathrm{mL}$ ). Very few men above the age of 75 years benefit from PSA testing.

${ }^{C}$ The reported median PSA values for men aged $40-49$ y range from $0.5-0.7 \mathrm{ng} / \mathrm{mL}$, and the 75 th percentile values range from $0.7-0.9 \mathrm{ng} / \mathrm{mL}$. Therefore, the PSA value of $1.0 \mathrm{ng} / \mathrm{mL}$ selects for the upper range of PSA values. Men who have a PSA above the median for their age group are at a higher risk for prostate cancer and for the aggressive form of the disease. The higher above the median, the greater the risk. Finally, men at age 60 years with a serum PSA $<1.0 \mathrm{ng} / \mathrm{mL}$ have a very low risk of metastases or death due to prostate cancer. Similarly, a cut point of $3.0 \mathrm{ng} / \mathrm{mL}$ at age 75 years also has a low risk of such outcomes.

PROSD-2

Version 2.2015, 07-09-15 @2015 National Comprehensive Cancer Network, Inc. All rights reserved. The NCCN Guidelines $₫$ and this illustration may not be reproduced in any form without the express written permission of $\mathrm{NCCN}^{\circledR}$. 
INDICATIONS FOR BIOPSY

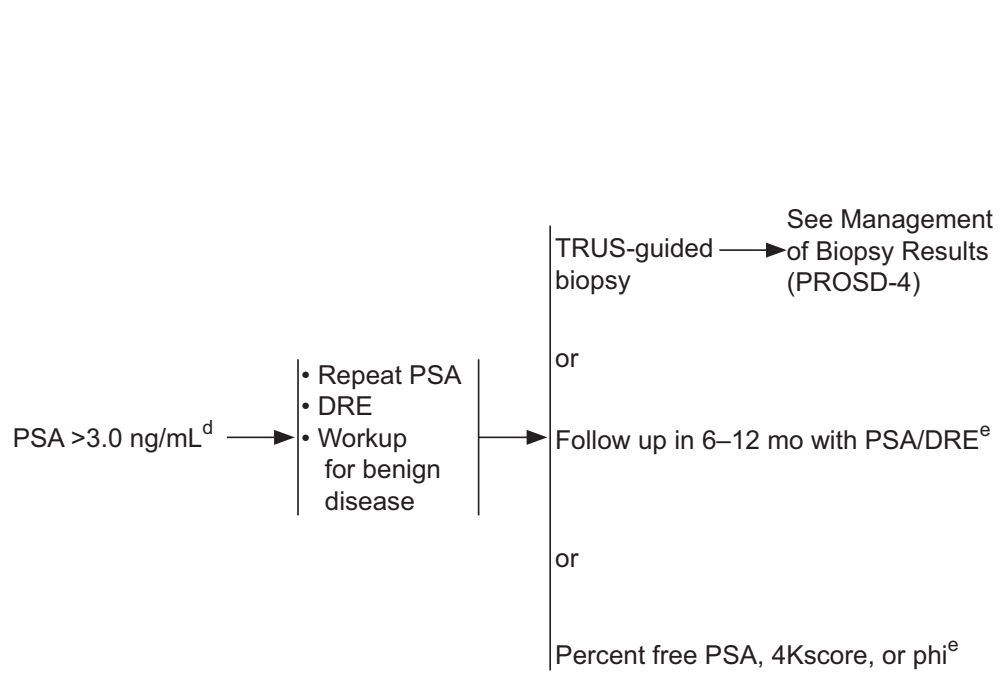

TRUS-GUIDED BIOPSY

Initial and Repeat

Extended-pattern biopsy (12 cores)

- Number of cores:

- Sextant (6),

- Lateral peripheral zone (6), and

- Lesion-directed at palpable nodule or suspicious image

- Anteriorly directed biopsy is not supported in routine biopsy. However, the addition of a transition zone biopsy to an extended biopsy protocol may be considered in a repeat biopsy if PSA is persistently elevated.

- Multiparametric MRI may help identify regions of cancer missed on prior biopsies and should be considered in selected cases after at least 1 negative biopsy.

- For high-risk men with negative biopsies, consideration can be given to a saturation biopsy strategy (including transperineal techniques) and/or the use of multiparametric MRI followed by an appropriate biopsy technique based on the results.

- Local anesthesia can decrease pain/discomfort associated with prostate biopsy and should be offered to all patients.

\footnotetext{
${ }^{\mathrm{d}}$ The level of PSA correlates with the risk of prostate cancer. The Prostate Cancer Prevention Trial (PCPT) demonstrated that $15 \%$ of men with a PSA level of $\leq 4.0 \mathrm{ng} / \mathrm{mL}$ and a normal DRE had prostate cancer diagnosed on end-of-study biopsies. Approximately $30 \%$ to $35 \%$ of men with serum PSA between 4 to $10 \mathrm{ng} / \mathrm{mL}$ will be found to have cancer. Total PSA levels $>10 \mathrm{ng} / \mathrm{mL}$ confer a greater than $67 \%$ likelihood of prostate cancer.

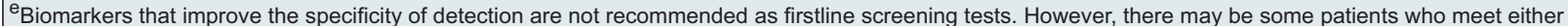
PSA or DRE standards for consideration of biopsy, but for whom the patient and/or the physician wish to further define the probability of high-grade cancer. A percent free PSA $<10 \%$, phi $>35$ or 4 Kscore (which provides an estimate of the probability of high-grade prostate cancer) are potentially informative in patients who have never undergone biopsy or after a negative biopsy; a PCA3 score $>35$ is potentially informative after a negative biopsy.
} 


\section{Prostate Cancer Early Detection, Version 2.2015}

\section{MANAGEMENT OF BIOPSY RESULTS}

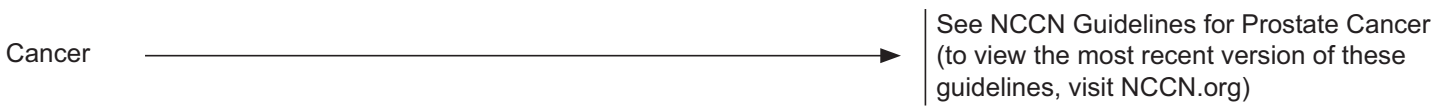

Atypia, suspicious for cancer

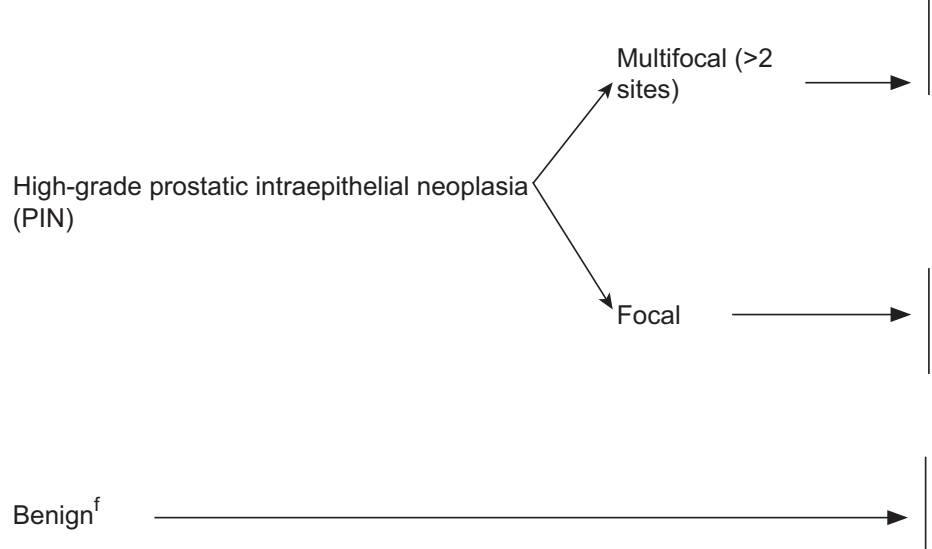

Extended pattern rebiopsy (within 6 mo) with increased sampling of the affected site and adjacent areas. If no cancer is found, close follow-up with PSA and DRE is recommended at 1-year interval initially

Follow with PSA and DRE at 1-year interval initially (see PROSD-2)

Repeat biopsy based on risk $^{f}$

Repeat biopsy based on follow-up in 6-12 mo with PSA/DRE or be followed with DRE and PSA. Tests which improve specificity in the post-biopsy state-including 4Kscore, phi, percent free PSA and PCA3 - should be considered in patients thought to be at a higher risk despite a negative biopsy (See PROSD-3). Emerging evidence suggests that the use of multiparametric $\mathrm{MRI}$ and/or the use of refined biopsy techniques (transperineal or saturation biopsies) may be of value as well. Also, as noted in the discussion section, PSA testing may be discontinued at certain ages and PSA cutpoints. 
ic antigen (PSA) testing for the early detection of prostate cancer in informed, healthy men in certain age groups. The panel bases this recommendation on level I evidence from randomized trials that showed a reduction in prostate cancer-specific mortality in men who underwent PSA screening.

However, the panel also uniformly acknowledges the risk of overdetection of otherwise indolent disease and the attendant risk of overtreatment, which exposes men to the potential morbidity of treatment without benefit. The panel concludes that these NCCN Guidelines for Prostate Cancer Early Detection should be used in conjunction with the NCCN Guidelines for Prostate Cancer (available at NCCN. org), which explicitly recommends active surveillance or observation for appropriate candidates.

\section{Literature Search Criteria and Guidelines Update Methodology}

Before the update of this version of the NCCN Guidelines for Prostate Cancer Early Detection, an electronic search of the PubMed database was performed to obtain key literature in the field of prostate cancer published between October 6, 2013, and October 6, 2014, using the following search terms: (prostate cancer) AND (screening OR early detection). The PubMed database was chosen because it remains the most widely used resource for medical literature and indexes only peer-reviewed biomedical literature. ${ }^{3}$

The search results were narrowed by selecting studies in humans published in English. Results were confined to the following article types: clinical trial, phase III; clinical trial, phase IV; guideline; randomized controlled trial; meta-analysis; and systematic reviews.

The PubMed search resulted in 172 citations, and their potential relevance was examined. The data from key PubMed articles and articles from additional sources (eg, e-publications ahead of print, meeting abstracts) deemed as relevant to these guidelines and discussed by the panel have been included in this version of the "Discussion." Recommendations for which high-level evidence is lacking are based on the panel's review of lower-level evidence and expert opinion.

The complete details of the "Development and Update of the NCCN Guidelines" are available on the NCCN website (NCCN.org).

\section{Types of Early Detection Testing}

\section{PSA Testing}

PSA is a glycoprotein secreted by prostatic epithelial cells, and its protease activity lyses the clotted ejaculate to enhance sperm motility. Although primarily confined to the seminal plasma, PSA enters the circulation through unknown mechanisms. Many commercially available sources of PSA antibodies for serum tests are available worldwide. With the exception of minor differences in the calibration of these assays, they perform comparably when used appropriately. However, PSA measures obtained using different commercial assays are not directly comparable or interchangeable, since the values are calibrated against different standards. If an abnormally high PSA level is observed, consideration should be given to repeat testing, particularly if the value is close to the threshold.

PSA is not a cancer-specific marker, and therefore most men with elevated PSA levels do not have prostate cancer. In fact, only about $25 \%$ of men with PSA in the 4 to $10 \mathrm{ng} / \mathrm{mL}$ range have a subsequent positive biopsy. ${ }^{4}$ Additionally, men with low PSA values have a significant chance of having prostate cancer. Using data from 18,882 men in the Prostate Cancer Prevention Trial (PCPT), Thompson et $\mathrm{al}^{5}$ determined the sensitivity and specificity of PSA levels for detecting any prostate cancer using various cut-offs. At $3.1 \mathrm{ng} / \mathrm{mL}$, PSA has a sensitivity of about $32 \%$ and a specificity of about $87 \%$.

Despite its limitations, recent population-based prostate cancer screening studies have shown survival benefits using PSA, sometimes in combination with digital rectal examination (DRE) or other ancillary tests, as discussed in more detail in the following sections.

Factors Affecting PSA Levels: PSA can be elevated due to infection, recent instrumentation, ejaculation, or trauma. However, empiric antibiotic use appears to have little value for improving test performance in asymptomatic men with an elevated PSA. ${ }^{6}$

The $5 \alpha$-reductase inhibitors (5-ARI) finasteride and dutasteride are commonly used to treat lower urinary tract symptoms due to benign prostatic hyperplasia $(\mathrm{BPH})$. Use and duration of 5-ARI therapy should be elicited carefully in the history, because this class of drugs typically results in an approximate $50 \%$ decrease in serum PSA levels within 6 to 12 
months of initiating therapy. ${ }^{7}$ However, this effect is tremendously variable. For example, one study showed that after 12 months of treatment, only $35 \%$ of men demonstrated the expected $40 \%$ to $60 \%$ decrease in PSA, while another $30 \%$ had greater than a $60 \%$ decrease. $^{8}$ Thus, the commonly employed method of doubling the measured PSA value to obtain an adjusted value may result in unreliable cancer detection.

In fact, failure to achieve a significant PSA decrease while taking 5-ARIs can indicate a heightened risk for prostate cancer that warrants regular testing. Results from several clinical trials suggested that 5-ARIs enhance the predictive capacity of PSA, ,,10 but reflex ranges for PSA among patients on 5-ARIs have not been established. The PCPT of 18,882 men demonstrated that finasteride reduced the incidence of prostate cancer by $25 \%$ compared with placebo. This reduction was almost exclusively for low-grade (Gleason sum 6) tumors; an increased proportion of aggressive (Gleason sum $\geq 7$ ) tumors was seen. ${ }^{11}$ However, after 18 years of follow-up, no significant group difference was seen in overall survival or survival after the diagnosis of prostate cancer in those on finasteride compared with the control group. ${ }^{12}$

In the Reduction by Dutasteride of Prostate Cancer Events (REDUCE) trial, PSA detected more high-grade tumors in the dutasteride arm, while the overall prostate cancer diagnosis fell by $23 \%$ compared with control. ${ }^{10}$ Similar to the PCPT trial, the difference in the number of high-grade cancers detected did not result in a mortality difference. ${ }^{13}$

A report on the Combination of Avodart (dutasteride) and Tamsulosin (CombAT) trial also showed a $40 \%$ lower incidence of prostate cancer with dutasteride plus tamsulosin (another BPH drug) compared with tamsulosin alone, along with a slightly improved yield of PSA-driven biopsy. ${ }^{14}$ Unlike the PCPT and REDUCE studies, diagnosis of high-grade (Gleason sum $\geq 7$ ) tumors was not increased. Overall, these studies suggest that PSA testing may have enhanced specificity for men receiving finasteride or dutasteride. Whether or not men should consider taking these agents for chemoprevention is beyond the scope of this guideline.

Ketoconazole, commonly used to treat fungal conditions, inhibits the androgen synthesis pathway and hence can also lower PSA levels. Since moderate PSA decreases have been seen with ketoconazole in the treatment of patients with prostate cancer after failure of hormonal therapy, ${ }^{15}$ recent ketoconazole use should also be noted in the history.

A health survey on 12,457 men visiting a prostate cancer screening clinic showed that more than $20 \%$ of men take herbal supplements, while only $10 \%$ take prescription medication (such as finasteride) for lower urinary tract symptoms. ${ }^{16}$ Several of these herbal supplements, such as saw palmetto, may contain phytoestrogenic compounds that can affect serum PSA levels. Very little is known about the exact composition of these herbal supplements and their specific effects on serum PSA levels.

Overall, appropriate use of PSA testing alone can provide a diagnostic lead-time of 5 to 10 years, but the lead-time varies across studies, populations, and screening protocols. ${ }^{17}$ Since the introduction of PSA testing, there has been an increase in the detection of early-stage, organ-confined disease and a decrease in disease that is metastatic at the time of diagnosis. ${ }^{18}$ The risk of prostate cancer increases with increasing PSA, but there is no level of PSA below which the risk of prostate cancer can be eliminated. The PCPT showed that $15 \%$ of men with a PSA level of $4.0 \mathrm{ng} / \mathrm{mL}$ or less and a normal DRE had prostate cancer (as diagnosed using end-of-study biopsies)..$^{19}$ Approximately $30 \%$ to $35 \%$ of men with serum PSAs in the 4 to $10 \mathrm{ng} / \mathrm{mL}$ range will be found to have cancer. Total PSA (tPSA) levels greater than $10 \mathrm{ng} / \mathrm{mL}$ confer a greater than $67 \%$ likelihood of biopsy-detectable prostate cancer. ${ }^{20}$

Controversies of PSA Testing: The decision about whether to pursue early detection of prostate cancer is complex. When, who, and how often to test remain major topics of debate. PSA screening has played a critical role in the downward migration of prostate cancer stage seen over the past decades. The incidence of metastatic disease at the time of diagnosis has decreased dramatically since 1988.21,22 As a result of early detection strategies, considerable stage migration has occurred in the past 2 decades in the United States. This trend has likely, but not definitely, contributed to a substantial reduction in prostate cancer mortality. ${ }^{23,24}$

Still, although prostate cancer is a major cause of death and disability in the United States, many argue that the benefits of early detection are, at best, moderate, and that early detection often results in overdetection. Overdetection is the identification of 
indolent disease, disease that would not be a problem for the patient if undetected or untreated. These arguments hold that overdetection may lead to overtreatment, which is aggressive treatment in men with a low probability of yielding clinical benefit.

In addition, PSA testing often produces falsepositive results, which in turn contribute to patient anxiety and the increased costs and potential complications associated with unnecessary biopsies. On the basis of its perception of the harm-benefit tradeoffs of prostate cancer screening, the US Preventive Services Task Force (USPSTF) has recommended against routine PSA testing. ${ }^{25}$

\section{DRE}

Best evidence supports the use of serum PSA for the early detection of prostate cancer. Still, many experts continue to recommend DRE for screening, as some clinically significant cancers may potentially be missed using a serum PSA cut-point alone. Studies have consistently shown that prostate cancer cases detected through PSA testing are more often confined to the prostate than those detected solely by DRE..$^{26,27}$ Currently, $81 \%$ of prostate cancers are pathologically organ-confined at time of diagnosis. ${ }^{28}$

Recent screening trials have either used DRE in conjunction with PSA for screening ${ }^{29}$ or as an ancillary test for patients who are found to have an elevated PSA. ${ }^{30,31}$ To elucidate the specific role of DRE in screening for prostate cancer, Gosselaar et $\mathrm{al}^{32}$ showed that among those with a serum PSA greater than $3 \mathrm{ng} / \mathrm{mL}$, those with a positive DRE were more likely to have prostate cancer. Furthermore, among 5519 men in the control arm of the PCPT, Thompson et $\mathrm{al}^{33}$ observed that an abnormal DRE increased the probability of cancer detection by almost 2.5 fold in multivariable analysis; the risk of high-grade disease was increased 2.7 fold with an abnormal DRE.

However, in men with normal PSA, the positive predictive value (PPV) of DRE is poor (about 4\%-11\%). ${ }^{34,35}$ Therefore, an abnormal DRE result alone as an indication for biopsy would lead to a large number of unnecessary biopsies and the detection of many insignificant cancers in men with low PSA values. In fact, in an analysis of 166,104 men with prostate cancer diagnosed between 2004 and 2007 from the SEER database, only $685(0.4 \%)$ had palpable, PSA-occult (PSA level of $<2.5 \mathrm{ng} / \mathrm{mL}$ ), Gleason score 8 to 10 prostate cancer. ${ }^{36}$

Overall, the panel believes that the value of DRE as a stand-alone test for prostate detection is limited, even though DRE picks up some cases of advanced cancer that would otherwise be missed. Therefore, the panel recommends DRE as a complementary test that may be considered with serum PSA in asymptomatic men who had a risk/benefit discussion and decided to pursue screening for prostate cancer. Furthermore, the panel believes that DRE should not be used as a stand-alone test without PSA testing. Finally, the panel believes that DRE should be performed in all men with an abnormal serum PSA to aid in decisions regarding biopsy (see "Pre-Biopsy Workup," page 1547).

\section{Population-Based Screening Studies}

Although many trials have been cited with regard to PSA testing, 2 studies are most relevant due to their topicality and randomized design.

\section{European Randomised Study of Screening for Prostate Cancer (ERSPC) Trial}

The ERSPC involved about 182,000 men between the ages of 50 and 74 years in 7 European countries, randomly assigned to a group that was offered PSA screening at an average of once every 4 years or to a control group that did not receive such screening; DRE or other ancillary tests were also performed in the screening group. ${ }^{31,37}$ The predefined core group included 162,388 men aged 55 to 69 years. Death from prostate cancer was the primary outcome. During a median follow-up of 11 years, the cumulative incidence of prostate cancer was $7.4 \%$ in the screening group versus $5.1 \%$ in the control group. There were 299 prostate cancer deaths in the screening group compared with 462 in the control group. The rate ratio for death from prostate cancer was 0.79 for the screening arm compared with the control arm (95\% CI, 0.68-0.91; $P=.001$ ). The investigators concluded that the PSA-based screening program reduced mortality from prostate cancer by $21 \%$. At the time of publication, the authors stated that 1055 men would need to be screened and 37 additional men would need to be treated over 11 years to prevent one prostate cancer death. Modeling the ERSPC data, however, Heijnsdijk et $\mathrm{al}^{38}$ estimated that the number needed to screen was 98 and the number needed to treat was 5 to prevent one prostate cancer death.

A recent report of 13-year follow-up of the ERSPC trial, with 7408 cases of prostate cancer di- 
agnosed in the screening arm and 6107 cases diagnosed in the control arm, confirmed these results. ${ }^{39}$ The unadjusted rate ratio for death from prostate cancer was 0.79 (95\% CI, 0.69-0.91) at 13 years. After adjusting for nonparticipation, the rate ratio of prostate cancer death was 0.73 (95\% CI, 0.61-0.88). The authors reported that, for 781 men invited for screening or 27 additional prostate cancers detected, one prostate cancer death could be averted. Furthermore, another analysis of these 13-year data found that fewer men were diagnosed with metastatic disease in the screening arm (incidence rate ratio, 0.60; 95\% CI, 0.52-0.70)..$^{40}$

The apparent risk reduction was also confirmed in a recent analysis of the Rotterdam section of the ERSPC trial, in which prostate cancer-specific mortality was reduced by $32 \% .^{41}$ This same group found that if one controlled for noncompliance and nonattendance, the risk of death due to prostate cancer can be reduced by up to $51 \% .{ }^{42}$

The Göteborg randomized population-based prostate cancer screening trial was initiated before and independently of the ERSPC, but some of its patients were reported as part of the ERSPC. ${ }^{30}$ Twenty thousand men aged 50 to 64 years were randomized to either a screening group invited for PSA testing every 2 years or to a control group not invited. The study is ongoing, with men who have not reached the upper age limit invited for PSA testing. In men randomized to screening, $76 \%$ attended at least one test. PSA testing in the general population was very low at the beginning (3\%), but increased over time.

During a median follow-up of 14 years, 1138 men in the screening group and 718 in the control group were diagnosed with prostate cancer, resulting in a cumulative prostate cancer incidence of $12.7 \%$ in the screening group and $8.2 \%$ in the control group (hazard ratio [HR], 1.64; 95\% CI, 1.50-1.80; $P<.0001)$. The rate ratio for death from prostate cancer was 0.56 (95\% CI, 0.39-0.82; $P=.002)$ in the screening compared with the control group. Overall, 293 men needed to be screened and 12 needed to be diagnosed to prevent one prostate cancer death over 14 years. This study shows that prostate cancer screening is acceptable to the Swedish population and that prostate cancer mortality was reduced almost by half over 14 years. In addition, it should be noted that a cause-specific survival benefit was noted despite the fact that not all cancers were immedi- ately treated. This result suggests that early detection combined with selective treatment based on risk can lower mortality rates without uniform treatment of all cancers.

Eighteen-year follow-up of the Göteborg trial was recently reported, with 1396 cases of prostate cancer in the screening arm and 962 cases in the control arm. ${ }^{43}$ The reduction in absolute prostate cancerspecific mortality was 0.72 (95\% CI, 0.50-0.94). The number needed to invite to prevent one death was 139 and the number needed to diagnose was 13.

There are several possible explanations for the more favorable results of the Göteborg trial compared to the Prostate, Lung, Colorectal, and Ovarian Cancer Screening (PLCO; see subsequent section) or ERSPC trials. First, the patients were younger and less likely to have incurable prostate cancer at first screening; second, there was less contamination of the control arm because PSA testing was uncommon in the Swedish population when the study began; third, a lower PSA threshold was used for recommending a biopsy; and finally, men were screened more frequently than ERSPC and for a longer period than PLCO. However, because more than half of the participants were included in the main analysis of ERSPC, the Göteborg trial should not be interpreted as a true independent confirmatory study. A recent analysis of the Göteborg trial showed that the risks of aggressive prostate cancer and prostate-cancer mortality became similar in the screening and control arms 9 years after the cessation of screening. ${ }^{44}$

In a similar fashion, the Finnish Prostate Cancer Screening Trial, the largest component of ERSPC, reported a small, non-statistically significant reduction in prostate cancer-specific death after 12 years of follow-up. ${ }^{45}$

\section{PLCO Trial}

The PLCO study randomized 76,685 men aged 55 to 74 years at 10 US study centers to annual screening (annual PSA for 6 years and DRE for 4 years) or usual care. ${ }^{46}$ After 13 years of follow-up, the incidence rate ratio for the screening arm compared with the control arm was 1.12 (95\% CI, 1.07-1.17). The investigators did not find a statistically significant difference between the disease-specific mortality rates of the screening and control groups (relative risk [RR], 1.09; 95\% CI, 0.87-1.36).

Despite the large sample size, this trial was flawed both by prescreening and the high contami- 
nation rate of $40 \%$ to $52 \%$ per year in the control group (ie, $74 \%$ of men in the usual care arm were screened at least once). The estimated mean number of screening PSAs (DREs) in the control arm was 2.7 (1.1) and 5.0 (3.5) in the screened arm. In addition, the biopsy rate for those with elevated serum PSA values was relatively low compared with the European trials. The PLCO trial thus really compared fixed screening versus "opportunistic" screening and, therefore, did not really test the hypothesis that screening with PSA is of value. However, it did show that yearly screening may be of limited value compared to less frequent testing. ${ }^{47}$

In a subset analysis reported by Crawford et al, ${ }^{48}$ a $44 \%$ decrease in the risk of prostate cancer-specific death was seen in men with no or minimal comorbidity assigned to screening compared to control, and the numbers needed to screen and treat to prevent one death were 723 and 5, respectively. This benefit was not found among men with one or more significant comorbidities. These results suggest that screening is more useful among men in good health due to the lack of competing cause for mortality. However, others suggest that such analysis is prone to major methodological errors. ${ }^{49}$

\section{Trial Limitations}

In addition to the limitations of the PLCO trial noted previously, these randomized controlled trials (RCTs) also share at least 3 additional limitations. First, they did not address the potential benefit of screening in men with high-risk factors. For instance, fewer than $5 \%$ of PLCO participants were of African-American descent and only 7\% reported a family history of prostate cancer. ${ }^{29}$ Therefore, it is not known whether men at higher risk may benefit more from screening than those at lower risk. Second, many men in these studies underwent sextant prostate biopsies rather than extended core biopsies, the standard diagnostic technique used today. The ERSPC may have underestimated benefit due to advanced age at first PSA test (median above 60), low intensity of screening (largely every 4 years) and, perhaps, suboptimal treatment available in Europe in the 1990s compared to what is available today.

The reduction in prostate cancer mortality must be balanced against the adverse effects of treatment, emphasizing the importance of selective rather than universal treatment of men with prostate cancer identified by screening. ${ }^{38}$

\section{Practical Considerations of Testing}

\section{Age at Which to Initiate Testing}

Controversy exists as to the ideal age to begin screening for prostate cancer. Recent randomized trials looking at the impact of screening on prostate cancer mortality have focused primarily on men aged 55 to 69 years. The ERSPC and Göteborg trials reported decreased disease-specific mortality in men aged 55 to 69 and 50 to 64 years, respectively. These results support baseline PSA testing in men aged 50 to 55 years with the strongest evidence supporting testing at age 55 .

As younger men were not included in these screening studies, baseline testing at earlier ages has not been evaluated in RCTs. However, observational evidence suggests that baseline testing of men in their 40s and early 50s may have value for future risk stratification, although some would describe the value as marginal. ${ }^{50} \mathrm{~A}$ study by Lilja et $\mathrm{al}^{51}$ assessed blood collected from 21,277 men in Sweden aged 33 to 50 years who were followed up until 2006. Among the 1312 cases of prostate cancer and 3728 controls without prostate cancer, these investigators reported that a single PSA test before age 50 years predicted subsequent prostate cancer up to 30 years later with a robust area under the curve (AUC) of 0.72 ( 0.75 for advanced prostate cancer).

A recent report clarified associations of age with the long-term risks of metastases. ${ }^{52}$ In this study, the risk of prostate cancer death was strongly correlated with baseline PSA in men aged 45 to 49 years and 51 to 55 years; $44 \%$ of the deaths in the analytic cohort occurred in men in the highest tenth of the distribution of PSA, suggesting that there may be a strong rationale for baseline testing in men younger than age 55 years.

Taken together, these results suggest that one could perform early, baseline testing and then determine the frequency of testing based on risk. Although many advocate earlier testing only in men thought to be at higher risk due to family history or race, as noted previously, a baseline serum PSA is a stronger predictor of the future risk of the disease compared with either of these risk factors.

Most panel members favor informed testing beginning at age 45 years. Repeat testing at 1 - to 2 -year intervals is recommended for men who have a PSA value $1.0 \mathrm{ng} / \mathrm{mL}$ or greater and at 2 - to 4 -year inter- 
vals for men with PSA less than $1 \mathrm{ng} / \mathrm{mL}$ (also see "Frequency of Testing," next section). This value is above the 75 th percentile for younger men $(<50$ years). ${ }^{53}$ The median PSA levels are $0.7 \mathrm{ng} / \mathrm{mL}$ and $0.9 \mathrm{ng} / \mathrm{mL}$ for ages 40 to 49 and ages 50 to 59 , respectively. ${ }^{54,55}$

\section{Frequency of Testing}

Current guidelines and recent screening trials have employed varying strategies with regards to the frequency of prostate cancer screening. The ideal screening interval to maximize mortality reduction yet minimize overdiagnosis remains uncertain.

A recent comparison of 2 centers involved in the ERSPC trial studied the impact of different screening intervals on the diagnosis of interval cancers in men aged 55 to 64 years. ${ }^{56}$ The Göteborg arm randomized 4202 men to screening every 2 years, while the Rotterdam arm randomized 13,301 men to screening every 4 years with similar follow-up of 11 to 12 years. Compared with screening every 4 years, there was a significant, $43 \%$ reduction in the diagnosis of advanced prostate cancer (clinical stage $>\mathrm{T} 3 \mathrm{a}$, $\mathrm{N} 1$, or M1; PSA $>20 \mathrm{ng} / \mathrm{mL}$; Gleason $>8$ at biopsy) for screening every 2 years. However, there was also a $46 \%$ increase in the diagnosis of low-risk prostate cancer (clinical stage T1c, Gleason $<6$, and PSA $<10 \mathrm{ng} / \mathrm{mL}$ at biopsy) for screening every 2 years.

Another study using micro-simulation models of prostate cancer incidence and mortality predicted that a strategy that utilizes biennial intervals in men with average PSA levels and longer screening intervals (every 5 years) for men with low PSA levels (below median for age by decade) allows a $2.27 \%$ risk of prostate cancer death compared to $2.86 \%$ from no screening. ${ }^{57}$ In addition, compared with annual screening and using a biopsy threshold of $4.0 \mathrm{ng} /$ $\mathrm{mL}$, the biennial strategy also projected a relatively lower over-diagnosis rate of $2.4 \%$ (vs $3.3 \%$ for annual screening), $59 \%$ reduction in total tests, and a $50 \%$ reduction in false-positive results. The biennial model was robust to sensitivity analyses, which varied the range of cancer incidence and survival attributed to screening.

Few studies have addressed the effect of PSA levels on the interval of testing, but it appears that men with a very low PSA could safely extend the testing interval. In the Rotterdam section of the ERSPC trial, men with a PSA less than $1 \mathrm{ng} / \mathrm{mL}$ had a very low risk for cancer at 4 and 8 years $(0.23 \%$ and
$0.49 \%) .{ }^{58}$ Other studies have shown that PSA values at younger ages strongly predict the development of or death from prostate cancer. ${ }^{55,59}$ For example, in a Swedish case-control study of 1167 men, those aged 60 years with PSA concentrations of $1 \mathrm{ng} / \mathrm{mL}$ or lower had only a $0.5 \%$ risk of metastasis by age 85 and $0.2 \%$ risk of death from prostate cancer. ${ }^{59}$

After considering these data, the panel concluded that tailoring screening intervals based on PSA levels might maximize survival advantage while decreasing the number of screenings and limiting over-diagnosis. The panel recommends repeat testing every 2 to 4 years if PSA is less than $1 \mathrm{ng} / \mathrm{mL}$ and every 1 to 2 years if PSA is $1 \mathrm{ng} / \mathrm{mL}$ or higher in men aged 45 to 75 years. The panel notes that a younger man on the higher end of PSA (eg, a 45-year-old man with PSA $0.9 \mathrm{ng} / \mathrm{mL}$ ) might be screened in 2 years, whereas an older man with a lower PSA might be screened in 4 years. Clinical judgment should be used.

\section{Age at Which to Discontinue Testing}

Even more elusive than identifying the ideal age at which to start screening is determining the ideal age at which to discontinue screening for men with normal PSA levels. Panelists uniformly agreed that PSA testing should only be offered to men with a 10 or more year life expectancy. However, panelists did not agree as to when to discontinue routine testing in asymptomatic older men. Furthermore, estimates of life expectancy can be refined using several resources such as life insurance tables. ${ }^{60-62}$ Physicians may not be accurate at estimating life expectancy and many tend to overvalue age and undervalue comorbidity. ${ }^{63,64}$

Since the previously cited RCTs (ESRPC, PLCO, and Göteborg) observed benefits to testing only in men aged up to 70 years, several panelists favored stopping testing at age 70 years. However, other data would suggest a benefit to screening beyond 70 years. A study of 4561 men who underwent radical prostatectomy found that men older than 70 years were more likely to have higher grade and stage of disease and worse survival compared with their younger counterparts. ${ }^{65}$ Others have published similar findings. ${ }^{66}$

To assess the appropriate ages for discontinuing screening, the previously cited microsimulation model ${ }^{57}$ predicted that decreasing the stopping age from 74 to 69 years would lead to a $27 \%$ relative re- 
Prostate Cancer Early Detection, Version 2.2015

duction in the probability of life saved, but an almost $50 \%$ reduction in the probability of over-diagnosis. This latter finding reflects the fact that a large proportion of men older than 70 years have cancer that would be unlikely to diminish their life expectancy and that screening in this population would substantially increase rates of overdetection, while also recognizing the increased prevalence of higher-risk cases in this age that could benefit from earlier detection.

The microsimulation model also assessed a strategy of screening men up to age 74 years while simultaneously increasing the PSA threshold for biopsy based on age-dependent PSA levels (ie, increasing the threshold level for biopsy with increasing age). Compared with using a uniform cut-off of $4.0 \mathrm{ng} /$ $\mathrm{mL}$, this strategy reduced the rate of over-diagnosis by one third while only slightly altering lives saved.

tPSA at certain ages may predict future risk. Vickers et $\mathrm{al}^{59}$ examined the relationship between baseline PSA at age 60 years and the future risk of prostate cancer death or metastases and found that those with PSA level below the median $(<1 \mathrm{ng} / \mathrm{mL})$ were unlikely to develop clinically significant prostate cancer $(0.5 \%$ risk of metastases and $0.2 \%$ risk of prostate cancer death). Similarly, in a study of 849 men in the Baltimore Longitudinal Study of Aging, no men aged 75 to 80 years with a PSA less than $3.0 \mathrm{ng} / \mathrm{mL}$ died of prostate cancer. ${ }^{67}$ Moreover, the time to death or diagnosis of aggressive prostate cancer was longer in men with a PSA less than $3.0 \mathrm{ng} /$ $\mathrm{mL}$ versus those with a PSA greater than $3.0 \mathrm{ng} / \mathrm{mL}$, suggesting that men 75 years or older with a PSA less than $3.0 \mathrm{ng} / \mathrm{mL}$ are unlikely to die or experience aggressive prostate cancer throughout their remaining life and may safely discontinue screening.

In summary, many possible strategies to reduce over-diagnosis in the older population exist. At this time, the panel supports screening in men until age 75 , and then continuing screening only in very select patients (category 2B). The panel notes that although some men in this older age group present with high-risk disease, very few men older than age 75 years benefit from PSA screening.

\section{Screening in High-Risk Populations}

African-American men and men with a first-degree relative with prostate cancer (especially cancer found at a younger age) have a higher risk of developing prostate cancer. ${ }^{68-72}$ In fact, having a first-degree relative with prostate cancer diagnosed before the age of 60 increases the likelihood of a prostate cancer diagnosis by 2.1 - to 2.5 -fold. . $^{71,72}$

Black men have a $64 \%$ higher incidence of prostate cancer and 2.3-fold increase in prostate cancer mortality compared with white men. ${ }^{68}$ Factors that contribute to this racial disparity may include differences in genetic risk factors, environmental exposures, and patient and physician behaviors; decreased access to high-quality health care including cancer early detection and follow-up care; delays in diagnosis; and suboptimal treatment. ${ }^{73-75}$

Whereas it is clear that African-American men and men with a family history of prostate cancer are at higher risk for prostate cancer incidence and mortality, the effects of intensive screening on cancer outcomes and on screening-related harms in these populations are not clear. Prostate cancer screening has been best studied in white men; data on screening in diverse and high-risk populations are lacking. In the PLCO trial, approximately $4.4 \%$ of the participants were African-American and $6.9 \%$ had a positive family history, but no subset analyses were performed. ${ }^{29}$ In the ERSPC trial, no information on race or family history was reported. ${ }^{31}$

In conclusion, African-American men and men with a family history of prostate cancer represent high-risk groups. However, the panel believes that current data are insufficient to inform the best strategy for prostate cancer screening in these populations and also note that a baseline PSA value is a stronger predictive factor than a positive family history or race. ${ }^{76,77}$ Therefore, although these individuals may require a higher level of vigilance and potentially different considerations when analyzing the results of screening tests, the panel does not give separate screening recommendations for these men at this time.

\section{Prostate Cancer Risk in Genetic Syndromes}

Some inherited syndromes increase the risk for prostate cancer. Germline BRCA1 and BRCA2 mutations (associated with hereditary breast and/or ovarian cancer syndrome) have been associated with an increased risk for prostate cancer in numerous reports. ${ }^{78-86}$ In particular, BRCA2 mutations have been associated with a 2 - to 6 -fold increase in the risk for prostate cancer, whereas the association of BRCA1 
mutations and increased risks for prostate cancer are less consistent. ${ }^{79,81,82,86-88}$ Furthermore, prostate cancer in men with germline BRCA mutations appear to have a more aggressive phenotype and is associated with significantly reduced survival times than in noncarrier patients. ${ }^{89-93}$ The NCCN Guidelines for Genetic/Familial High-Risk Assessment: Breast and Ovarian (available at NCCN.org) recommend that men with BRCA2 mutations start prostate cancer screening at age 40 and that men with BRCA1 mutations consider the same.

In addition, men with Lynch syndrome (germline mutations in MLH1, MSH2, MSH6, PMS2, or EPCAM) have a 2- to 5-fold increase in risk for prostate cancer. ${ }^{94-98}$ Age of onset and aggressiveness of prostate cancer in these individuals, however, do not appear to be different than in sporadic cases. ${ }^{95}$ Currently, the NCCN Guidelines for Genetic/Familial High-Risk Assessment: Colorectal (available at NCCN.org) do not list any specific prostate cancer screening recommendations for men with Lynch syndrome.

Results from the first round of screening of the IMPACT study, which enrolled men aged 40 to 69 years with germline BRCA1/2 mutations and a control group of men with wild-type BRCA1/2 who are related to mutation carriers, were recently reported. ${ }^{99}$ Whereas no difference between carriers and controls in the rate of prostate cancer detection or the PPV of biopsy for detecting cancer in men with PSA greater than $3.0 \mathrm{ng} / \mathrm{mL}$ was evident, a significant difference was seen in the PPV of biopsy for detecting intermediate/high-grade cancer in BRCA2 carriers with PSA greater than $3.0 \mathrm{ng} / \mathrm{mL}(2.4 \%$ vs $0.7 \% ; P=.04)$. Future rounds of screening in this trial may help inform the best strategy for screening in this high-risk population.

\section{Indications for Biopsy}

The previously cited RCTs used PSA thresholds to prompt a biopsy. PSA cut-points for biopsy varied somewhat between centers and trials over time. Although a serum PSA of $2.5 \mathrm{ng} / \mathrm{mL}$ has been used by many, a level of $3 \mathrm{ng} / \mathrm{mL}$ is supported by the trials and would more robustly limit the risk of overdetection. However, some panel members did not recommend limiting the option of biopsy to prespecified PSA thresholds, noting that there are many other fac- tors (eg, age, race, family history, PSA kinetics) that should also inform the decision to perform biopsy.

The panel does not believe that DRE alone should be an absolute indication for biopsy in men with low PSA. The PPV of DRE in men with low PSA is poor (see DRE, in previous sections). ${ }^{35,100}$ Clinical judgment should be used.

\section{Pre-Biopsy Workup}

The panel recommends that any man with a PSA greater than $3 \mathrm{ng} / \mathrm{mL}$ undergo workup for benign disease, a repeat PSA, and a DRE to inform decisions about whether to proceed with transrectal ultrasound (TRUS)-guided biopsy. A DRE in this setting of elevated PSA has a high predictive value. ${ }^{32}$ The roles of imaging and biomarker testing are discussed in the next section.

Risk Calculators: Prostate cancer risk calculators have been developed to estimate an individual's risk for prostate cancer from multiple factors. Common calculators are the Sunnybrook-, ERSPC-, and PCPTbased risk calculators. ${ }^{33,101-104}$ These online tools combine clinical variables - including but not limited to age, family history, race, DRE, and PSA - to estimate both the risk for biopsy-detectable prostate cancer and the risk for biopsy-detectable high-grade prostate cancer. Such information potentially allows for more informed decision-making. ${ }^{105}$ However, such calculators have not been assessed in RCTs, and cut-points of risk associated with reductions in prostate cancer mortality remain unknown. Such calculators have as much value in determining who might not need biopsy as in identifying those at higher risk. At this time, the panel does not recommend the use of risk calculators alone to determine whether biopsy is indicated. Clinical judgment and patient preferences need to be taken into consideration.

\section{Imaging}

The Prostate Imaging Reporting and Data System (PI-RADS) from the American College of Radiology gives recommendations for high-quality MRI in prostate cancer care, including recommendations related to the use of MRI to direct targeted biopsies. ${ }^{106}$ In addition, the European Society of Urogenital Radiology established guidelines for optimal multiparametric MRI of the prostate, including for detection and targeted biopsies. ${ }^{107}$ Overall, the panel empha- 
sizes the need for high-quality MRI and for radiologic expertise for optimal reading of scans.

\section{Novel Imaging Techniques}

There is considerable interest in the use of novel MRI imaging, most notably multiparametric MRI, to select those who need a prostate biopsy or to guide needle placement during the biopsy, although data supporting its use are limited. ${ }^{108-110}$ The goals of using MRI to inform the decision to perform biopsy include reducing the number of men undergoing biopsy, reducing the detection of indolent disease (and thus the risks of overdetection and overtreatment), and improving the detection of clinically significant disease through targeted biopsies. Current data, however, do not conclusively show that MRI achieves these goals.

In a prospective study of 223 biopsy-naïve men with elevated PSA, all men had standard TRUS biopsies in addition to multiparametric MRI. ${ }^{109} \mathrm{Par}$ ticipants with suspicious or equivocal lesions (PIRADS 3-5) then underwent MRI-guided biopsy. TRUS biopsies detected 126 of 142 cases of cancer (88.7\%) including 47 cases classified as low risk. The MRI-guided biopsies identified an additional 16 cases of intermediate/high-risk prostate cancer and led to the reclassification of 13 cases from low risk to intermediate/high risk. Thus, the addition of multiparametric MRI with targeted biopsies for suspicious or equivocal lesions to standard biopsy allowed the identification of clinically significant disease in an additional $13 \%$ of the study population. The authors also determined the effects of using multiparametric MRI to decide whether to biopsy. Not biopsying men with PI-RADS $1 / 2$ would reduce the number of men requiring biopsy by $36 \%$, reduce the identification of low-risk prostate cancer by $87 \%$, and increase the yield of intermediate/high-risk tumors by $18 \%$, but would have missed 15 intermediate/high-risk tumors (6.7\% of study population).

A single-center trial randomized 130 biopsynaïve men to a control group that received TRUSguided random biopsy alone or to a group that received prebiopsy multiparametric MRI, TRUSguided random biopsy, and cognitive MRI/TRUS fusion targeted biopsy. ${ }^{110}$ The primary outcome was not met, with similar rates of detection of prostate cancer $(64 \%$ vs $57 \% ; P=.5)$ and of clinically significant cancer ( $55 \%$ vs $45 \% ; P=.8$ ) in the 2 arms. Additional clinical trials are underway to assess the value of MRI imaging for diagnosis in the prebiopsy setting (eg, NCT02131207).

Another prospective study included 347 patients with findings suspicious for prostate cancer, many of whom had 1 or more previous negative biopsies. ${ }^{108}$ All patients received a multiparametric MRI, and those with abnormal findings proceeded to MRITRUS fusion targeted biopsies. The outcome was defined as improved detection in targeted cores, with significantly more cancer detected in targeted cores than in systematic biopsies (30\% vs $8.2 \%$ ). About $12 \%$ of men without MRI-suspicious lesions were diagnosed with intermediate-risk tumors. In this study, the cancer detection rate was $51 \%$ in men with previous negative biopsies.

In a prospective cohort study of 1003 men undergoing both MRI-targeted and standard biopsy, Siddiqui et $\mathrm{al}^{111}$ noted that the targeted biopsy strategy was associated with the detection of high-risk cancer and the decreased detection of low-risk cancer. Thus, the panel strongly believes that MRI alone should not be used to decide whether to perform biopsy and emphasizes that a negative MRI is not an indication to forego biopsy in a man with indications for first-time biopsy. All men with indications for biopsy should receive the standard 12-core TRUSguided biopsy regardless of MRI results. Based on the studies described previously, it is estimated that the use of MRI to exclude men from biopsies may lead to as many as $12 \%$ of significant cancers being missed, although the available data to date are not conclusive.

The panel also does not uniformly recommend that MRI-guided targeted biopsies be used in place of or in addition to standard 12-core TRUS biopsies in the initial biopsy setting. More information is needed in such a setting. However, the panel believes that multiparametric MRI may help identify regions of cancer missed on previous biopsies and should be considered in selected cases of men with at least 1 negative biopsy (also see "Repeat Biopsies," page 1552).

\section{Biomarker Testing: PSA Derivatives and Other Tests}

When the first recommendations for early detection programs for prostate cancer were made, serum tPSA was the only PSA-based test available. PSA deriva- 
tives and other assays exist that potentially improve the specificity of testing and thus may diminish the probability of unnecessary biopsies.

When a patient meets the standards for biopsy, sometimes the patient and physicians wish to further define the probability of cancer before proceeding to biopsy with its associated risks (see "Risks of Biopsy," page 1554). Several biomarker tests have been developed with the goals of refining patient selection for biopsies, decreasing unnecessary biopsies, and increasing the specificity of cancer detection, without missing a substantial number of higher-grade (Gleason $\geq 7$ ) cancers. These tests may be especially useful in men with PSA levels between 3 and $10 \mathrm{ng} / \mathrm{mL}$. Most often, these tests have been used in patients who have had one negative biopsy to determine if repeat biopsy is an appropriate consideration.

The panel recommends consideration of percent free PSA (\%f PSA), 4Kscore test, and Prostate Health Index (phi) in patients with PSA levels greater than $3 \mathrm{ng} / \mathrm{mL}$ who have not yet had a biopsy. \%f PSA, 4Kscore, phi, and prostate cancer gene 3 (PCA3) test may also be considered for men who have had at least one prior negative biopsy and are thought to be at higher risk. Results of any of these tests, when performed, should be included in discussions between clinician and patient to assist in decisions regarding whether to proceed with biopsy. These and other tests are discussed below.

\section{Age- and Race-Specific PSA Reference Ranges}

Age-specific PSA reference ranges were introduced by Oesterling et $\mathrm{al}^{112}$ as a method to increase cancer detection (ie, increase sensitivity) in younger men by lowering PSA cutoffs for biopsy and to decrease unnecessary biopsies (ie, improve specificity) in older men by increasing PSA cutoffs. ${ }^{112-114}$ Several groups have investigated these age-specific ranges with equivocal results. Others have suggested racespecific reference ranges. ${ }^{115}$ However, the exact roles of these age- and race-specific PSA cutoffs in the early detection of prostate cancer remain unclear. The panel has no recommendations regarding routine use of these ranges.

\section{PSA Velocity}

The rate of change in PSA over time is broadly termed PSA velocity (PSAV), determined by at least 3 separate PSA values calculated over at least an 18 -month period. Carter et $\mathrm{a}^{116}$ first showed that
PSAV is greater in men eventually diagnosed with prostate cancer than in men not diagnosed with the disease and suggested its use as a screening tool. In a subsequent study of 980 men enrolled in the Baltimore Longitudinal Study of Aging (BLSA), Carter et al explicitly linked PSAV with the risk of prostate cancer death by observing that PSAV recorded 10 to 15 years before cancer diagnosis (commonly with PSA $<4 \mathrm{ng} / \mathrm{mL}$ ) was associated with disease-specific survival up to 25 years later: the RR of prostate cancer death was higher in men with PSAV greater than $0.35 \mathrm{ng} / \mathrm{mL} /$ year compared with those with PSAV $0.35 \mathrm{ng} / \mathrm{mL} /$ year or lower (RR, 4.7; 95\% CI, 1.3-16.5; $P=.02) .{ }^{117}$ These data provide support that PSAV may help identify lethal cases. However, the small number of deaths from prostate cancer (20) precludes definitive conclusions.

In two other studies of men with prostate cancer, ${ }^{118,119}$ very high PSAV ( $\left.>2 \mathrm{ng} / \mathrm{mL} / \mathrm{y}\right)$ during the year before diagnosis was associated with a greatly increased risk of death from the disease, but this is a much higher cutoff for PSAV than the one proposed by Carter et al.

Vickers et $a l,{ }^{120}$ however, have questioned the role of PSAV in tumor detection among men with low PSA levels. The analysis was performed on 5519 men undergoing biopsy regardless of indication in the control arm of the PCPT to explore the additional yield from a PSAV threshold of $0.35 \mathrm{ng} / \mathrm{mL} /$ year. The main finding of this study was that PSAV did not significantly increase the predictive accuracy of high PSA levels or positive DRE and might substantially increase the number of men recommended for biopsy. However, these findings should be applied only to men similar to those studied in PCPT $(\geq 55$ years of age; $96 \%$ Caucasian-American; 17\% family history of prostate cancer; PSA values $\leq 3$ at enrollment). ${ }^{33} \mathrm{~A}$ recent report suggests that screening strategies that used PSAV at low PSA levels were more likely to suffer from overdiagnosis and falsepositive tests resulting in more harm relative to incremental lives saved. ${ }^{57}$

Panelists disagree as to the value of PSAV alone as a criterion for considering biopsy when the PSA level is low $(<2.0 \mathrm{ng} / \mathrm{mL})$. Due to its potential capacity to identify tumors with lethal potential, most panelists agree that PSAV (PSAV $\geq 0.35 \mathrm{ng} / \mathrm{mL} / \mathrm{y}$ ) is only one criterion to consider when deciding whether to perform biopsy for men with low PSA 
levels. Panelists do not agree as to the threshold of PSAV that should prompt consideration of biopsy, but agree that high PSAV alone, at low PSA levels, does not mandate biopsy but rather should aid in the decision-making process. Other factors such as age, comorbidity, race, and family history also should be considered.

In a recently reported study of men pursuing a second biopsy after an initial negative biopsy, PSAV was an independent predictor of overall prostate cancer, intermediate, and high-grade cancer. ${ }^{121}$ Panelists would also like to draw attention to the following caveats: the predictive value of PSAV can be influenced by PSA level ${ }^{33,118,122}$; PSAV is not useful in patients with very high $(>10 \mathrm{ng} / \mathrm{mL})$ PSA values ${ }^{123}$; PSAV measurements can be confounded by prostatitis, a condition that can cause dramatic and abrupt increases in PSA levels; ${ }^{124}$ and fluctuations among measurements can occur as a result of either laboratory interassay variability related to the use of different commercially available sources or individual biologic variability. Thus, an abnormal PSA result should be confirmed by retesting.

\section{$\%$ fPSA}

Unbound or free PSA (fPSA), expressed as a ratio of tPSA, is a clinically useful molecular form of PSA, with the potential to improve early detection, staging, and monitoring of prostate cancer. Several molecular forms of PSA are known to circulate in the blood. In most men, the majority $(60 \%-90 \%)$ of circulating PSA is covalently bound to endogenous protease inhibitors. Most immunoreactive PSA is bound to the protease inhibitor alpha-1-antichymotrypsin. Other immunoreactive PSA-protease inhibitor complexes, such as alpha-1-antitrypsin and protease $\mathrm{C}$ inhibitor, exist at such low serum concentrations that their clinical significance has not been determined. In addition, a large proportion of PSA is complexed with alpha-2-macroglobulin (AMG). Unfortunately, this PSA-AMG complex cannot be measured by conventional assays because of the shielding (or "caging") of PSA antigenic epitopes by AMG.

Most clinical work investigating the use of the molecular forms of PSA for early detection of prostate cancer has focused on the percentage of PSA found circulating in the free or unbound form. $\mathrm{Nu}$ merous studies have shown that the percentage of serum $\mathrm{fPSA}$ (\% PSA) is significantly lower in men who have prostate cancer compared with men who do not.

The FDA approved the use of \%f PSA for the early detection of prostate cancer in men with PSA levels between $4 \mathrm{ng} / \mathrm{mL}$ and $10 \mathrm{ng} / \mathrm{mL}$. The multiinstitutional study that characterized the clinical utility of this assay showed that a $25 \%$ fPSA cutoff detected $95 \%$ of prostate cancers while avoiding $20 \%$ of unnecessary prostate biopsies. ${ }^{125}$

Since its approval by the FDA, testing for \%f PSA has gained widespread clinical acceptance in the United States, specifically for patients with normal DREs who have previously undergone prostate biopsy because they had a tPSA level within the "diagnostic gray zone."

\section{Complexed forms of PSA}

PSA exists in free and several complexed forms. Direct measurement of the complexed form with alpha-1-antichymotrypsin is now available. For practical purposes, tPSA consists essentially of fPSA and the alpha-1-antichymotrypsin complexed form (cPSA). The threshold levels are therefore not equivalent: cPSA levels of $2.2 \mathrm{ng} / \mathrm{mL}$ and $3.4 \mathrm{ng} /$ $\mathrm{mL}$ are equivalent to tPSA levels of $2.5 \mathrm{ng} / \mathrm{mL}$ and $4.0 \mathrm{ng} / \mathrm{mL}$, respectively. In a multicenter trial of 831 men, of whom 313 had prostate cancer, researchers found that cPSA in the range of $80 \%$ to $95 \%$ sensitivity thresholds increased specificity compared with tPSA. ${ }^{126}$ Results were similar for percent cPSA and percent fPSA.

Therefore, the ratio of cPSA to tPSA should provide information comparable to the fPSA to tPSA ratio. ${ }^{127}$ Other studies also demonstrated an enhanced specificity of cPSA within certain tPSA ranges. ${ }^{128-130}$ Use of cPSA has been approved as an aid in the detection of prostate cancer in men aged 50 years or older in conjunction with DRE. However, because cPSA has not gained widespread acceptance in day-to-day clinical practice, it has not been incorporated into these algorithms.

\section{PSA Density}

PSA density (PSAD) requires the measurement of prostate volume by TRUS and is expressed as the PSA value (in $\mathrm{ng} / \mathrm{mL}$ ) divided by prostate volume (in cc). PSAD is a means of discriminating prostate cancer from BPH: the lower the PSAD, the greater the probability of BPH. ${ }^{131,132}$ Thus, PSAD potentially identifies men who do not have prostate cancer but 
have high PSA secondary to large-volume prostates. A PSAD cutoff of $0.15 \mathrm{ng} / \mathrm{mL} / \mathrm{cc}$ was recommended in earlier studies, which spared as many as $50 \%$ of men from unnecessary biopsies. However, some subsequent studies have reported that the 0.15 cutoff has insufficient sensitivity. ${ }^{133}$

More recent studies have tried to improve on the performance of PSAD by using CPSA $^{134}$ or PSSA $^{135}$ in the numerator or correcting the denominator for transition zone volume. ${ }^{136}$ The clinical utility of these methodologies remains unclear.

PSAD has also been shown to correlate with prostate cancer presence and aggressiveness and may predict adverse pathology and biochemical progression after treatment. ${ }^{137,138}$ The lack of precision of measurement of both PSA and prostate volume has prevented the widespread clinical acceptance of PSAD. In addition, studies have shown that \%f PSA provides results comparable to PSAD in earlydetection algorithms. ${ }^{139}$

Although the panel recognizes that PSAD may explain an elevated PSA value considered after negative biopsies, it has not incorporated PSAD into the early detection guidelines as a baseline measure because PSAD alone may offer little added benefit over other tests and requires ultrasound. Still, the panel agrees that PSAD has been clinically underused and may be considered in evaluating patients, especially those who have had prior ultrasound-determined measurements of prostate volume.

\section{PCA3}

PCA3 is a noncoding, prostate tissue-specific RNA that is overexpressed in prostate cancer. Current assays quantify PCA3 overexpression in post-DRE urine specimens. PCA3 appears useful in predicting biopsy outcomes at both initial and repeat biopsies. However, it appears most useful in determining which patients should undergo a repeat biopsy. ${ }^{140-143}$

Results were recently reported from an NCI Early Detection Research Network (EDRN) validation study of the PCA3 urinary assay in 859 men scheduled for a diagnostic prostate biopsy in 11 centers. ${ }^{144}$ The primary outcomes were reported at a PPV of $80 \%$ (95\% CI, 72\%-86\%) in the initial biopsy setting and a negative predictive value (NPV) $88 \%$ (95\% CI, 81\%-93\%) in the repeat biopsy setting. Based on the data, use of PCA3 in the repeat biopsy setting would reduce the number of biopsies by almost half, and $3 \%$ of men with a low PCA3 score would have high-grade prostate cancer that would be missed. ${ }^{145}$ In contrast, the risk of high-grade disease in men without prior biopsy with a low PCA3 is $13 \%$. Thus, the panel believes that this test in not appropriate to use in the initial biopsy setting. The FDA has approved the PCA3 assay to help decide, along with other factors, whether a repeat biopsy in men age 50 years or older with one or more previous negative prostate biopsies is necessary.

\section{phi}

Development of novel biomarkers continues. The phi is a combination of existing tests (ie, tPSA, fPSA, proPSA). ${ }^{146-148}$ In a multicenter study, it was noted to have approximately double the sensitivity of fPSA/tPSA for cancer detection in those with serum PSA concentrations between 2 and $10 \mathrm{ng} / \mathrm{mL} .{ }^{149}$ In addition, the phi correlated with cancer grade and had an AUC of 0.72 for discrimination of high-grade (Gleason 27 ) cancer from low-grade cancer or negative biopsy. The phi was approved by the FDA for use in 2012 in those with serum PSA values between 4 and $10 \mathrm{ng} / \mathrm{mL}$.

\section{Kscore}

The 4 Kscore test is another combination test that measures free and tPSA, human kallikrein 2 (hK2), and intact PSA and also considers age, DRE results, and prior biopsy status. ${ }^{150,151}$ This test reports the percent likelihood of finding high-grade (Gleason $\geq 7$ ) cancer on biopsy. A prospective multi-institutional US trial of 1012 patients showed that 4Kscore results have a high discrimination value (AUC, 0.82). ${ }^{152} \mathrm{In}$ this study, using a threshold for biopsy of $15 \%$ or greater risk allowed for 591 biopsies to be avoided (58\%), while 183 high-grade tumors were detected and 48 high-grade tumors (4.7\% of the 1012 participants) were missed. When 4 Kscore was examined in 6129 men in another prospective study, the AUC was also 0.82 (95\% CI, 0.80-0.84). ${ }^{153}$ Using a $6 \%$ risk of high-grade cancer as a cutoff, 428 of 1000 men could avoid biopsy, with 119 of 133 high-grade cancers detected and 14 of 133 missed.

The 4Kscore test is not FDA approved; instead it is considered a laboratory developed test through one CLIA-accredited testing laboratory in Nashville, Tennessee. The panel consensus is that the test can be considered for patients before biopsy and for those with prior negative biopsy for men thought to be at higher risk for clinically significant prostate 
cancer. It is important for patients and their urologists to understand, however, that no cut-off threshold has been established for the 4 Kscore. If a 4 Kscore test is performed, the patient and his urologist should discuss the results to decide whether to proceed with a biopsy.

\section{ConfirmMDx}

ConfirmMDx is a tissue-based, multiplex epigenetic assay that aims to improve the stratification of men being considered for repeat prostate biopsy. Hypermethylation of the promoter regions of GSTP1, APC, and RASSF1 are assessed in core biopsy tissue samples. The test, performed in one CLIA-certified laboratory, is not FDA approved.

The European MATLOC study blindly tested this assay in archived tissue from 498 men with negative biopsies who had repeat biopsies within 30 months. ${ }^{154}$ The NPV was 90\% (95\% CI, 87\%-93\%). In multivariate analysis, ConfirmMDx was predictive of patient outcome (OR, 3.17; 95\% CI, 1.815.53). A similar validation study was performed in the United States using archived tissue from 350 men with negative biopsies who underwent repeat biopsies within 24 months. ${ }^{155}$ The NPV was $88 \%$ (95\% CI, 85\%-91\%), and the test was again found to be predictive of outcomes on multivariate analysis (OR, 2.69; 95\% CI, 1.60-4.51).

Despite the good NPV of this test, the panel noted that the study population included only patients who were ultimately selected for repeat biopsy. Furthermore, the panel noted that the NPV of first negative biopsy alone is already in the range of $75 \%$ to $80 \%$ and questioned the true value added by the test results. Therefore, until prospective data for this test or data comparing this test to other tests are available, the panel does not recommend its use.

\section{Biopsy Technique}

\section{Initial Biopsy}

Systematic prostate biopsy under TRUS guidance is the recommended technique for prostate biopsy. Initially described as a sextant technique sampling both right and left sides from the apex, mid-gland, and base in the mid-parasagittal plane, more recently extended biopsy schemes have shown improved cancer detection rates. Although no one scheme is considered optimal for all prostate shapes and sizes, most emphasize better sampling of the lateral and anterior aspects of the peripheral zone. One commonly used scheme is the 12-core biopsy scheme that includes a standard sextant as well as a lateral sextant scheme (ie, lateral apex, lateral mid-gland, lateral base). This scheme has been validated and results in enhanced cancer detection compared to sextant biopsy schemes. ${ }^{156,157}$

The panel recommends that an extended-pattern-at least 12-core-biopsy be done (sextant medial and lateral peripheral zone and lesion-directed). Anteriorly directed biopsy is not supported in routine biopsy. However, this can be added to an extended biopsy protocol in a repeat biopsy if PSA is persistently elevated.

Interest in the use of novel imaging, particularly MRI, to guide needle placement during biopsy (see "Imaging," page 1547, and "Targeted Biopsy Techniques" in the subsequent section) has increased recently. ${ }^{158}$ Until these methods are validated in ongoing clinical trials, however, the panel does not recommend specific imaging techniques other than TRUS for initial biopsy. They can be considered in the setting of repeat biopsy, as discussed in the next section.

In addition, there is interest in saturation approaches to biopsy (often image-guided) to improve diagnostic accuracy. ${ }^{159}$ However, at present the panel does not recommend routine use of transperineal biopsy for initial biopsy, although it can be considered in the repeat biopsy setting (see "Saturation Biopsy Techniques," next page).

\section{Repeat Biopsies}

A negative biopsy does not preclude a diagnosis of prostate cancer on subsequent biopsy. If clinical suspicion of cancer persists after a negative biopsy, consideration can be given to saturation biopsy strategies and/or the use of multiparametric MRI followed by an appropriate targeted biopsy technique based on the results. In addition, biomarker testing can also be considered in these men to inform decisions regarding repeat biopsy (see "Biomarker Testing: PSA Derivatives and Other Tests," page 1548).

Targeted Biopsy Techniques: Targeted biopsy techniques include cognitive or visual targeting (guiding with ultrasound based on an MRI image), TRUSMRI fusion platforms (merging a stored MRI image with a real-time ultrasound image), and direct in-bore 
MR-guided biopsy (performed by an interventional radiologist while the patient is in the scanner). ${ }^{158,160,161}$

After 1 or more negative TRUS biopsies, men who are considered at high risk (eg, those with persistently elevated or rising PSA) can be considered for MRI followed by targeted biopsy based on several studies showing improved detection of clinically significant prostate cancer in this setting. ${ }^{108,162-168} \mathrm{Re}$ ported cancer detection rates by targeted fusion biopsies in men with previous negative biopsies range from $34 \%$ to $51 \% .{ }^{108,163-165}$ Studies that used direct MR guidance for targeted biopsies report similar cancer detection rates in men with previous negative biopsies: $41 \%$ to $56 \%{ }^{166-168}$

The targeted biopsy approach may lead to a higher rate of detection of clinically significant cancer in men with prior negative biopsy, in contrast to repeat systematic biopsies, which lead to the identification of more low-risk tumors. For instance, in one retrospective cohort study, 105 men with prior negative biopsies and elevated PSA underwent multiparametric MRI followed by standard 12-core systematic biopsy and MR-US fusion targeted biopsy regardless of MRI results. ${ }^{164}$ Prostate cancer was found in 36 men (34\%). In this study, 21 of 23 cancers (91\%) identified by targeted biopsy were significant (Gleason $3+4$ or mean core length $\geq 4 \mathrm{~mm}$ ), compared with 15 of 28 cancers (54\%) identified by standard biopsy. Targeted biopsies missed 2 cases of clinically significant cancer compared with 5 missed cases with standard biopsies.

In a prospective study, 583 patients (56\% with prior negative biopsy) underwent multiparametric MRI. ${ }^{169}$ All men received systematic 12 -core biopsies, and men with lesions seen on MRI also received fusion-guided biopsies. Multivariate analysis revealed that a higher MRI suspicious score increased the likelihood of finding Gleason 7+ cancer by 3.3fold (95\% CI, 2.2-5.1; $P<.0001$ ).

In another prospective study, 1003 men with elevated PSA or abnormal DRE underwent multiparametric MRI to identify suspicious regions followed by targeted TRUS-MRI fusion biopsy and concurrent standard biopsy. ${ }^{111}$ When possible, biopsy results were compared with whole-gland pathology after prostatectomy. Whereas the 2 biopsy approaches yielded similar numbers of prostate cancer cases, the targeted approach identified 30\% more high-risk cancers (173 vs 122 cases, $P<.001)$ and $17 \%$ fewer low-risk cancers (213 vs 258 cases, $\mathrm{P}<.001)$ com- pared with the standard approach. In the 170 men with whole-gland pathology, the predictive ability of targeted biopsy for differentiating low- from intermediate- or high-risk disease was superior to that of standard biopsy and the 2 approaches combined (AUC, 0.73 vs 0.59 vs 0.67 , respectively; $\mathrm{P}<.05$ for all comparisons).

Saturation Biopsy Techniques: In saturation biopsies, 20 cores or more (usually 22-24) are collected systematically across the entire prostate in hopes of improving prostate cancer detection over that of a standard 12-core biopsy. Saturation biopsies can be performed via transrectal or transperineal approaches, the latter of which is often image-guided (see "Targeted Biopsy Techniques," previous section). The approaches seem to have similar rates of cancer detection. ${ }^{170}$ In fact, one study compared the approaches head-to-head and found similar cancer detection rates in the repeat biopsy setting $(31.4 \%$ for transrectal vs $25.7 \%$ for transperineal; $P=.3) .{ }^{171}$ The transperineal approach may have a lower risk of infection, may allow for better saturation of the gland, and may be more acceptable to patients compared with the transrectal approach. ${ }^{172}$ In fact, recent studies reported zero or near-zero rates of sepsis in men biopsied with the transperineal approach. ${ }^{173-175}$ Another possible benefit of the transperineal over the transrectal approach is more accurate staging. ${ }^{176}$ However, the transperineal approach may be associated with a higher rate of urinary retention. ${ }^{172}$ The transrectal approach can be performed in the office.

A study of transperineal template-guided mapping biopsy found detection rates of $55.5 \%, 41.7 \%$, and $34.4 \%$ for men with 1,2 , and 3 or more previous negative biopsies, respectively. ${ }^{177}$ Other groups have reported similar rates of detection using saturation biopsies in men with previous negative biopsies. ${ }^{175,178,179}$

Compared with an extended biopsy approach (12-14 cores), one prospective, nonrandomized study found that transrectal saturation biopsy detected significantly more cancers in men with 1 previous negative biopsy $(32.7 \%$ vs $24.9 \% ; P=.0075) .{ }^{180}$ The detection of insignificant cancer did not differ significantly between the groups ( $40.1 \%$ vs $32.6 \% ; P=.2)$.

Based on this emerging evidence, the panel believes that a saturation biopsy strategy can be considered for men with previous negative biopsies at very high risk . 


\section{Risks of Biopsy}

The problem of repeated biopsies is gaining attention in the PSA debate, due to increasing concerns about the risks of complications, particularly drug-resistant Escherichia coli infections. ${ }^{181}$ The range of potential infectious complications includes urinary tract infection (UTI), epididymitis, orchitis, prostatitis, and sepsis. Other morbidities include rectal bleeding, hematuria, vasovagal episodes, fever, hematospermia, and dysuria. ${ }^{182,183}$

In an analysis of data from 17,472 men in the SEER database, prostate biopsy was associated with a 2.7fold increased risk of 30-day hospitalization. ${ }^{184}$ These investigators also reported that while the incidence of infectious complications after prostate biopsy has increased significantly in recent years, the incidence of noninfectious complications has remained relatively stable. These results are similar to those from a Canadian study of 75,190 men who were biopsied, in which the hospitalization rate increased from 1.0\% in 1996 to $4.1 \%$ in $2005 . .^{185}$ About $70 \%$ of all admissions were related to infections. A recent analysis of the PLCO trial, however, noted that biopsy complications were infrequent and that biopsy was not associated with a higher risk of mortality. ${ }^{186}$

Fluoroquinolones, particularly ciprofloxacin, are used commonly as a prophylaxis for TRUS biopsy. Recent studies have reported that about half of postbiopsy infections are resistant to fluoroquinolone, many of which are also resistant to other antibiotics. ${ }^{187,188} \mathrm{Re}$ sistance is associated with prior prophylactic exposure to fluoroquinolone. ${ }^{189,190}$ Although these infections will respond to cephalosporins, measures are needed to prevent additional resistant strains. One strategy is to develop more stringent criteria for biopsy. Another proposed strategy is to selectively target antibiotic prophylaxis with prebiopsy rectal culture. ${ }^{191}$

Up to $90 \%$ of men undergoing a prostate biopsy have reported some discomfort during the procedure. ${ }^{192}$ Both topical lidocaine gel and an injectable nerve block have been shown to be safe and efficacious for reducing discomfort. ${ }^{193,194}$ Topical lidocaine was more efficacious in reducing pain during probe insertion, whereas periprostatic injection reduced pain during the biopsy itself. These minor anesthetic techniques greatly enhance the acceptability of the procedure, particularly with extended templates and saturation techniques, but should be considered in all patients. ${ }^{195}$ For exceptional cases, such as for men with anal strictures or patients who have received inadequate pain block with a periprostatic injection, intravenous sedation or general anesthesia may be advantageous.

\section{NCCN Recommendations}

\section{General Considerations}

The decision to participate in an early detection program for prostate cancer is complex for both the patient and physician. Important factors must be assessed when considering early detection of prostate cancer, including patient age, life expectancy, family history, race, and previous early detection test results (see "Screening in High-Risk Populations," page 1546). Most importantly, the patient and physician need to understand the risks and benefits associated with the early detection and treatment of prostate cancer. Several general principles for early detection should be clearly understood before using the NCCN Guidelines:

- No portion of these early detection guidelines is designed to replace an accurate history and complete physical examination conducted by a physician.

- The general health, medical comorbidities, life expectancy, and preferences of the patient are paramount when recommending or designing an early detection program.

- Prostate cancer risk factors, such as family history and race (ie, African-American men), should be considered before decisions are made concerning the initiation of an early detection program (see Screening in "HighRisk Populations").

- Prostate cancer in its early stages has no identifiable symptoms. In advanced disease, symptoms may include urinary obstruction, prostatic bleeding, hematospermia, and bone pain. Although most men wishing to take part in early detection programs have no symptoms of prostate cancer, they may have mild to severe symptoms of lower urinary tract disease because of benign prostatic enlargement. Care should be taken to educate patients about the distinction between these diseases when discussing the risks and benefits associated with early detection. 
- A patient's history of prior testing, including DRE, PSA, PSA derivatives, and prostate biopsy, should be assessed when considering early detection.

- A thorough discussion on the pros and cons of testing must be carried out between the physician and the potential participant as outlined in the algorithm. Patients should be informed that the purpose of screening is to find aggressive cancers, that screening often detects low-risk cancers, and that such lowrisk cancers may not need treatment but can be managed by active surveillance. Decision aids are available. ${ }^{196}$

- The panel uniformly feels that these guidelines need to be linked to the NCCN Guidelines for Prostate Cancer (available at NCCN.org).

- The panel recommends that baseline PSA testing should be offered to healthy, wellinformed men aged 45 to 75 years based on the results of RCTs. Baseline testing may be complemented by DRE.

- The panel recommends frequency of testing be 2 to 4 years for men aged 45 to 75 years with serum PSA values below $1 \mathrm{ng} / \mathrm{mL}$. For men with PSA at or exceeding $1.0 \mathrm{ng} / \mathrm{mL}$, testing should occur at 1- to 2-year intervals.

- The panel recommends that biopsy should be considered in those aged 45 to 75 years with a serum PSA greater than $3.0 \mathrm{ng} / \mathrm{mL}$. However, most panel members agree that a decision to perform a biopsy should not be based on a PSA cut-point alone, but should incorporate other important clinical variables including age, family history, PSA kinetics, race, health status, and patient preference.

- The panel recommends that PSA testing be considered only in very select patients after the age of 75 years (category 2B) and that indication for biopsy be carefully evaluated. Panel members uniformly discourage PSA testing in men unlikely to benefit from prostate cancer diagnosis based on age and/or comorbidity.

- The panel recommends that consideration may be given to biomarkers that improve biopsy specificity such as \%f PSA, 4Kscore, and phi before biopsy in men with serum PSA levels of greater than $3 \mathrm{ng} / \mathrm{mL}$ who desire more specificity. These tests and PCA3 are also options in men being considered for repeat biopsy after an initially benign result.

\section{Interpretation of Biopsy Results}

Cancer: Patients diagnosed with prostate cancer by biopsy should be managed according to the NCCN Guidelines for Prostate Cancer (available at NCCN. org). Among men diagnosed with cancer on prostate biopsy, the panel does not recommend routine repeat biopsy, except in special circumstances, such as the suspicion that the patient harbors more aggressive cancer than was evident on the initial biopsy and the patient is otherwise a candidate for active surveillance as outlined in the treatment guidelines. High-Grade Prostatic Intraepithelial Neoplasia: Approximately $10 \%$ of patients undergoing biopsy will be found to have high-grade prostatic intraepithelial neoplasia (HGPIN) ${ }^{197}$ Cytologically, the nuclear features of HGPIN resemble that of malignant tumors; however, the presence of a basal layer on the acini distinguishes this entity from cancer.

Extended biopsy schemes have resulted in a dramatic decline in the prevalence of cancer detected from a repeat biopsy in patients with HGPIN detected from the initial biopsy. Although reports in the sextant biopsy era demonstrated cancer rates of approximately 50\%, contemporary series using extended biopsy schemes report rates of approximately $10 \%$ to $20 \%$ and occasionally higher. ${ }^{198-200}$

Interestingly, the rates of cancer with repeat biopsy in such patients seem to be little different than in those who undergo repeat biopsy based on other risk factors, such as age, family history, and PSA. In addition, most detected cancers are low grade. ${ }^{201}$ If extended biopsies were used initially, only those at high risk for more aggressive cancer should undergo repeat biopsy. ${ }^{202}$ It is recommended that those with multifocal HGPIN undergo repeat biopsy within 6 months, with increased sampling of the affected site and adjacent areas. ${ }^{203}$

Atypia, Suspicious For Cancer: Distinct from HGPIN, in which a basal cell layer is present, atypia is characterized by small single-cell layer acini. Unlike HGPIN, which is a distinct pathologic diagnosis, atypia represents one of two possibilities: normal prostate tissue distorted by artifact or prostate can- 
cer that does not meet the histologic criteria for a diagnosis of prostate cancer. Because so few glands are present on the biopsy specimen, an unequivocal diagnosis of cancer cannot be established.

Even in the era of extended biopsy schemes, the prevalence of cancer detected from a repeat biopsy in patients with atypia detected from the initial biopsy is quite high: $50 \%$ or more, with the most likely area of cancer detection residing in the prostate area demonstrating atypia from the initial biopsy. ${ }^{204,205}$ Therefore, the panel recommends a repeat extended biopsy scheme within 6 months of an initial atypia diagnosis, with additional cores obtained from the region demonstrating atypia. If no cancer is found on the repeat biopsy, close follow-up with PSA (with consideration of complementary DRE) is recommended.

Benign Results: If a biopsy returns as negative for cancer, the panel recommends 2 options for followup: repeat PSA and DRE in 6 months with biopsy based on results or \% PSA, 4Kscore, phi, or PCA3 testing to inform the decision about performing a repeat biopsy. As discussed in detail previously, multiparametric MRI, targeted biopsies, or saturation biopsy techniques may also be considered in the evaluation of such patients.

\section{Summary}

Since the early 1990s, many variants of the tPSA assay have been introduced in attempts to increase the sensitivity of screening programs or cancer detection while maintaining specificity (elimination of unnecessary biopsies). These NCCN Guidelines recommend a method by which individuals and their physicians can use these new techniques rationally for the early detection of prostate cancer. These guidelines are not designed to provide an argument for the use of population screening programs for prostate cancer. Rather, they are meant to provide a vehicle by which early detection efforts can be practiced in an evidence-based, systematic fashion in patients who choose to participate in such programs. Whether to treat a patient on diagnosis is beyond the scope of these guidelines (see the NCCN Guidelines for Prostate Cancer, available at NCCN.org).

These NCCN Guidelines for Prostate Cancer Early Detection incorporate many recently validated findings if and when they occur. The panel will re- examine the clinical utility of new modalities annually, and the guidelines will be modified accordingly. In addition, future iterations of these guidelines may incorporate new serum markers currently undergoing clinical investigation.

The goal of NCCN and the Panel in updating these algorithms is to assist men and clinicians in choosing a program of early detection for prostate cancer and in making decisions regarding the need for prostate biopsy. Any clinician who uses these guidelines is expected to exercise independent medical judgment in the context of the individual clinical circumstances to determine the patient's need for prostate biopsy. These guidelines will continue to evolve as the field of prostate cancer advances.

\section{References}

1. Siegel RL, Miller KD, Jemal A. Cancer statistics, 2015. CA Cancer J Clin 2015;65:5-29.

2. National Cancer Institute. Surveillance, Epidemiology and End Results (SEER) Cancer Statistics Review, 1975-2004. 2007. Available at: http:// seer.cancer.gov/csr/1975_2004/. Accessed April 26, 2012.

3. U.S. National Library of Medicine-Key MEDLINE® Indicators. Available at: http://www.nlm.nih.gov/bsd/bsd_key.html. Accessed July 24, 2014.

4. Catalona WJ, Partin AW, Slawin KM, et al. Use of the percentage of free prostate-specific antigen to enhance differentiation of prostate cancer from benign prostatic disease: a prospective multicenter clinical trial. JAMA 1998;279:1542-1547.

5. Thompson IM, Ankerst DP, Chi C, et al. Operating characteristics of prostate-specific antigen in men with an initial PSA level of $3.0 \mathrm{ng} / \mathrm{ml}$ or lower. JAMA 2005;294:66-70.

6. Eggener SE, Large MC, Gerber GS, et al. Empiric antibiotics for an elevated prostate-specific antigen (PSA) level: a randomised, prospective, controlled multi-institutional trial. BJU international 2013;112:925-929.

7. D'Amico AV, Roehrborn CG. Effect of $1 \mathrm{mg} /$ day finasteride on concentrations of serum prostate-specific antigen in men with androgenic alopecia: a randomised controlled trial. Lancet Oncol 2007;8:21-25.

8. Brawer MK, Lin DW, Williford WO, et al. Effect of finasteride and/or terazosin on serum PSA: results of VA Cooperative Study \#359. Prostate 1999;39:234-239.

9. Gomella LG, Roherborn CG, Andriole GL, et al. Effect of dutasteride on the detection of prostate cancer in men with benign prostatic hyperplasia in the combination of dutasteride and tamsulosin (CombAT) trial [abstract]. Presented at the ASCO Genitourinary Cancers Symposium; May 5-7, 2010; San Francisco, CA. Abstract 28

10. Andriole GL, Bostwick DG, Brawley OW, et al. Effect of dutasteride on the risk of prostate cancer. N Engl J Med 2010;362:1192-1202.

11. Thompson IM, Goodman PJ, Tangen CM, et al. The influence of finasteride on the development of prostate cancer. N Engl J Med 2003;349:215-224.

12. Thompson IM, Jr., Goodman PJ, Tangen CM, et al. Long-term survival of participants in the prostate cancer prevention trial. The New England journal of medicine 2013;369:603-610.

13. Pinsky PF, Black A, Grubb R, et al. Projecting prostate cancer mortality in the PCPT and REDUCE chemoprevention trials. Cancer 2013;119:593601.

14. Roehrborn CG, Andriole GL, Wilson TH, et al. Effect of dutasteride on prostate biopsy rates and the diagnosis of prostate cancer in men with lower urinary tract symptoms and enlarged prostates in the Combination of Avodart and Tamsulosin trial. Eur Urol 2011;59:244-249.

15. Small EJ, Halabi S, Dawson NA, et al. Antiandrogen withdrawal alone or in combination with ketoconazole in androgen-independent prostate cancer patients: a phase III trial (CALGB 9583). J Clin Oncol 2004;22:1025-1033. 
16. Barqawi A, Gamito E, O'Donnell C, Crawford ED. Herbal and vitamin supplement use in a prostate cancer screening population. Urology 2004;63:288-292.

17. Draisma G, Etzioni R, Tsodikov A, et al. Lead time and overdiagnosis in prostate-specific antigen screening: importance of methods and context. J Natl Cancer Inst 2009;101:374-383.

18. Aus G, Bergdahl S, Lodding P, et al. Prostate cancer screening decreases the absolute risk of being diagnosed with advanced prostate cancer--results from a prospective, population-based randomized controlled trial. Eur Urol 2007;51:659-664

19. Thompson IM, Pauler DK, Goodman PJ, et al. Prevalence of prostate cancer among men with a prostate-specific antigen level $<$ or $=4.0 \mathrm{ng}$ per milliliter. N Engl J Med 2004;350:2239-2246.

20. Catalona WJ, Smith DS, Ratliff TL, et al. Measurement of prostate-specific antigen in serum as a screening test for prostate cancer. N Engl J Med 1991;324:1156-1161

21. Clegg LX, Li FP, Hankey BF, et al. Cancer survival among US whites and minorities: a SEER (Surveillance, Epidemiology, and End Results) Program population-based study. Arch Intern Med 2002;162:1985-1993.

22. Paquette EL, Sun L, Paquette LR, et al. Improved prostate cancer-specific survival and other disease parameters: impact of prostate-specific antigen testing. Urology 2002;60:756-759.

23. Etzioni R, Gulati R, Tsodikov A, et al. The prostate cancer conundrum revisited: treatment changes and prostate cancer mortality declines. Cancer 2012;118:5955-5963.

24. Chou R, LeFevre ML. Prostate cancer screening-the evidence, the recommendations, and the clinical implications. JAMA 2011;306:27212722 .

25. Moyer VA. Screening for prostate cancer: U.S. Preventive Services Task Force recommendation statement. Annals of internal medicine 2012;157:120-134.

26. Catalona WJ, Richie JP, Ahmann FR, et al. Comparison of digital rectal examination and serum prostate specific antigen in the early detection of prostate cancer: results of a multicenter clinical trial of 6,630 men. J Urol 1994;151:1283-1290

27. Catalona WJ, Smith DS, Ratliff TL, Basler JW. Detection of organ confined prostate cancer is increased through prostate-specific antigenbased screening. JAMA 1993;270:948-954

28. Brawley OW. Trends in prostate cancer in the United States. J Natl Cancer Inst Monogr 2012;2012:152-156.

29. Andriole GL, Crawford ED, Grubb RL, 3rd, et al. Mortality results from a randomized prostate-cancer screening trial. N Engl J Med 2009;360:1310 1319 .

30. Hugosson J, Carlsson S, Aus G, et al. Mortality results from the Goteborg randomised population-based prostate-cancer screening trial. Lancet Oncol 2010;11:725-732

31. Schroder FH, Hugosson J, Roobol MJ, et al. Screening and prostate-cancer mortality in a randomized European study. N Engl J Med 2009;360:1320_ 1328.

32. Gosselaar C, Roobol MJ, Roemeling S, Schroder FH. The role of the digital rectal examination in subsequent screening visits in the European randomized study of screening for prostate cancer (ERSPC), Rotterdam. European urology 2008;54:581-588.

33. Thompson IM, Ankerst DP, Chi C, et al. Assessing prostate cancer risk: results from the Prostate Cancer Prevention Trial. J Natl Cancer Inst 2006;98:529-534.

34. Flanigan RC, Catalona WJ, Richie JP, et al. Accuracy of digital rectal examination and transrectal ultrasonography in localizing prostate cancer. J Urol 1994;152:1506-1509.

35. Schroder FH, van der Maas P, Beemsterboer P, et al. Evaluation of the digital rectal examination as a screening test for prostate cancer. Rotterdam section of the European Randomized Study of Screening for Prostate Cancer. J Natl Cancer Inst 1998;90:1817-1823.

36. Hattangadi JA, Chen MH, D'Amico AV. Early detection of high-grade prostate cancer using digital rectal examination (DRE) in men with a prostate-specific antigen level of $<2.5 \mathrm{ng} / \mathrm{mL}$ and the risk of death. BJU international 2012;110:1636-1641.

37. Schroder FH, Hugosson J, Roobol MJ, et al. Prostate-cancer mortality at 11 years of follow-up. N Engl J Med 2012;366:981-990.

38. Heijnsdijk EA, Wever EM, Auvinen A, et al. Quality-of-life effects of prostate-specific antigen screening. N Engl J Med 2012;367:595-605.

39. Schroder FH, Hugosson J, Roobol MJ, et al. Screening and prostate cancer mortality: results of the European Randomised Study of Screening for
Prostate Cancer (ERSPC) at 13 years of follow-up. Lancet 2014;384:20272035.

40. Buzzoni C, Auvinen A, Roobol MJ, et al. Metastatic prostate cancer incidence and prostate-specific antigen testing: new insights from the European Randomized Study of Screening for Prostate Cancer. Eur Urol 2015:68:885-890.

41. Roobol MJ, Kranse R, Bangma $\mathrm{CH}$, et al. Screening for prostate cancer: results of the rotterdam section of the European randomized study of screening for prostate cancer. Eur Urol 2013;64:530-539.

42. Bokhorst LP, Bangma $\mathrm{CH}$, van Leenders GJ, et al. Prostate-specific antigen-based prostate cancer screening: reduction of prostate cancer mortality after correction for nonattendance and contamination in the Rotterdam section of the European Randomized Study of Screening for Prostate Cancer. Eur Urol 2014;65:329-336.

43. Arnsrud Godtman R, Holmberg E, Lilja H, et al. Opportunistic testing versus organized prostate-specific antigen screening: outcome after 18 years in the Goteborg Randomized Population-based Prostate Cancer Screening Trial. Eur Urol 2015;68:354-360.

44. Grenabo Bergdahl A, Holmberg E, Moss S, Hugosson J. Incidence of prostate cancer after termination of screening in a population-based randomised screening trial. Eur Urol 2013;64:703-709.

45. Kilpelainen TP, Tammela TL, Malila N, et al. Prostate cancer mortality in the Finnish randomized screening trial. J Natl Cancer Inst 2013;105:719725.

46. Andriole GL, Crawford ED, Grubb RL 3rd, et al. Prostate cancer screening in the randomized Prostate, Lung, Colorectal, and Ovarian Cancer Screening Trial: mortality results after 13 years of follow-up. J Natl Cancer Inst 2012;104:125-132.

47. Andriole GL. Update of the prostate, lung, colorectal, and ovarian cancer screening trial. Recent Results Cancer Res 2014;202:53-57.

48. Crawford ED, Grubb R, 3rd, Black A, et al. Comorbidity and mortality results from a randomized prostate cancer screening trial. J Clin Oncol 2011;29:355-361.

49. Bach PB, Vickers AJ. Do the data support the comorbidity hypothesis for the Prostate, Lung, Colorectal, and Ovarian Cancer Screening Trial Results? J Clin Oncol 2011;29:e387.

50. Howard K, Barratt A, Mann GJ, Patel MI. A model of prostate-specific antigen screening outcomes for low- to high-risk men: information to support informed choices. Arch Int Med 2009;169:1603-1610.

51. Lilja H, Cronin AM, Dahlin A, et al. Prediction of significant prostate cancer diagnosed 20 to 30 years later with a single measure of prostatespecific antigen at or before age 50. Cancer 2011;117:1210-1219.

52. Vickers AJ, Ulmert D, Sjoberg DD, et al. Strategy for detection of prostate cancer based on relation between prostate specific antigen at age 40-55 and long term risk of metastasis: case-control study. BMJ 2013;346:f2023.

53. Capitanio U, Perrotte P, Zini L, et al. Population-based analysis of normal total PSA and percentage of free/total PSA values: results from screening cohort. Urology 2009; 73:1323-1327.

54. Chun FK, Hutterer GC, Perrotte P, et al. Distribution of prostate specific antigen (PSA) and percentage free PSA in a contemporary screening cohort with no evidence of prostate cancer. BJU Int 2007;100:37-41.

55. Ulmert D, Cronin AM, Bjork T, et al. Prostate-specific antigen at or before age 50 as a predictor of advanced prostate cancer diagnosed up to 25 years later: a case-control study. BMC Med 2008;6:6

56. van Leeuwen PJ, Roobol MJ, Kranse R, et al. Towards an optimal interval for prostate cancer screening. European urology 2012;61:171-176.

57. Gulati R, Gore JL, Etzioni R. Comparative effectiveness of alternative prostate-specific antigen--based prostate cancer screening strategies: model estimates of potential benefits and harms. Ann Intern Med 2013;158:145153.

58. Roobol MJ, Roobol DW, Schroder FH. Is additional testing necessary in men with prostate-specific antigen levels of $1.0 \mathrm{ng} / \mathrm{mL}$ or less in a population-based screening setting? (ERSPC, section Rotterdam). Urology 2005;65:343-346.

59. Vickers AJ, Cronin AM, Bjork $\mathrm{T}$, et al. Prostate specific antigen concentration at age 60 and death or metastasis from prostate cancer: casecontrol study. BMJ 2010;341:c4521.

60. Social Security Administration. Period Life Table. 2009. Available at: http://www.ssa.gov/OACT/STATS/table4c6.html. Accessed March 10, 2014.

61. Howard DH. Life expectancy and the value of early detection. J Health Econ 2005;24:891-906. 
62. Lee SJ, Lindquist K, Segal MR, Covinsky KE. Development and validation of a prognostic index for 4-year mortality in older adults. JAMA 2006;295:801-808

63. Daskivich TJ, Chamie K, Kwan L, et al. Overtreatment of men with lowrisk prostate cancer and significant comorbidity. Cancer 2011;117:20582066.

64. Daskivich TJ, Chamie K, Kwan L, et al. Comorbidity and competing risks for mortality in men with prostate cancer. Cancer 2011;117:4642-4650.

65. Sun L, Caire AA, Robertson CN, et al. Men older than 70 years have higher risk prostate cancer and poorer survival in the early and late prostate specific antigen eras. J Urol 2009;182:2242-2248.

66. Bechis SK, Carroll PR, Cooperberg MR. Impact of age at diagnosis on prostate cancer treatment and survival. J Clin Oncol 2011;29:235-241.

67. Schaeffer EM, Carter HB, Kettermann A, et al. Prostate specific antigen testing among the elderly-when to stop? J Urol 2009;181:1606-1614; discussion 1613-1604.

68. SEER Stat Fact Sheets: Prostate Cancer. 2015. Available at: http://seer. cancer.gov/statfacts/html/prost.html. Accessed April 28, 2015.

69. Bratt O. Hereditary prostate cancer: clinical aspects. J Urol 2002;168:906913.

70. Carter BS, Beaty TH, Steinberg GD, et al. Mendelian inheritance of familial prostate cancer. Proc Natl Acad Sci U S A 1992;89:3367-3371.

71. Chen YC, Page JH, Chen R, Giovannucci E. Family history of prostate and breast cancer and the risk of prostate cancer in the PSA era. Prostate 2008;68:1582-1591.

72. Grill S, Fallah M, Leach RJ, et al. Incorporation of detailed family history from the Swedish Family Cancer Database into the PCPT risk calculator. J Urol 2015;193:460-465.

73. Barocas DA, Grubb R 3rd, Black A, et al. Association between race and follow-up diagnostic care after a positive prostate cancer screening test in the prostate, lung, colorectal, and ovarian cancer screening trial. Cancer 2013;119:2223-2229.

74. Mahal BA, Aizer AA, Ziehr DR, et al. Trends in disparate treatment of African American men with localized prostate cancer across National Comprehensive Cancer Network risk groups. Urology 2014;84:386-392.

75. Zhang $\mathrm{H}$, Messing EM, Travis LB, et al. Age and racial differences among PSA-detected (AJCC Stage T1cNOMO) prostate cancer in the U.S.: a population-based study of 70,345 men. Front Oncol 2013;3:312.

76. Mondo DM, Roehl KA, Loeb S, et al. Which is the most important risk factor for prostate cancer: race, family history, or baseline PSA level? [abstract]. J Urol 2008;179:Abstract 417.

77. Vertosick EA, Poon BY, Vickers AJ. Relative value of race, family history and prostate specific antigen as indications for early initiation of prostate cancer screening. J Urol 2014;192:724-728.

78. Cancer risks in BRCA 2 mutation carriers. The Breast Cancer Linkage Consortium. J Natl Cancer Inst 1999;91:1310-1316.

79. Agalliu I, Gern R, Leanza S, Burk RD. Associations of high-grade prostate cancer with BRCA1 and BRCA2 founder mutations. Clin Cancer Res 2009;15:1112-1120.

80. Ford D, Easton DF, Bishop DT, et al. Risks of cancer in BRCA1-mutation carriers. Breast Cancer Linkage Consortium. Lancet 1994;343:692-695.

81. Gallagher DJ, Gaudet MM, Pal P, et al. Germline BRCA mutations denote a clinicopathologic subset of prostate cancer. Clin Cancer Res 2010;16:2115-2121.

82. Kirchhoff T, Kauff ND, Mitra N, et al. BRCA mutations and risk of prostate cancer in Ashkenazi Jews. Clin Cancer Res 2004;10:2918-2921.

83. Leongamornlert D, Mahmud N, Tymrakiewicz M, et al. Germline BRCA1 mutations increase prostate cancer risk. Br J Cancer 2012;106:1697-1701.

84. Liede A, Karlan BY, Narod SA. Cancer risks for male carriers of germline mutations in BRCA1 or BRCA2: a review of the literature. J Clin Oncol 2004;22:735-742.

85. Tulinius H, Olafsdottir GH, Sigvaldason $H$, et al. The effect of a single BRCA2 mutation on cancer in Iceland. J Med Genet 2002;39:457-462.

86. van Asperen CJ, Brohet RM, Meijers-Heijboer EJ, et al. Cancer risks in BRCA2 families: estimates for sites other than breast and ovary. J Med Genet 2005;42:711-719.

87. Mersch J, Jackson MA, Park M, et al. Cancers associated with BRCA1 and BRCA2 mutations other than breast and ovarian. Cancer 2015;121:269275.

88. Moran A, O'Hara C, Khan S, et al. Risk of cancer other than breast or ovarian in individuals with BRCA1 and BRCA2 mutations. Fam Cancer 2012;11:235-242.
89. Castro E, Goh C, Olmos D, et al. Germline BRCA mutations are associated with higher risk of nodal involvement, distant metastasis, and poor survival outcomes in prostate cancer. J Clin Oncol 2013;31:1748-1757.

90. Mitra A, Fisher C, Foster CS, et al. Prostate cancer in male BRCAl and BRCA2 mutation carriers has a more aggressive phenotype. $\mathrm{Br} \mathrm{J}$ Cancer 2008;98:502-507.

91. Narod SA, Neuhausen $S$, Vichodez G, et al. Rapid progression of prostate cancer in men with a BRCA2 mutation. Br J Cancer 2008;99:371-374.

92. Thorne H, Willems AJ, Niedermayr E, et al. Decreased prostate cancerspecific survival of men with BRCA2 mutations from multiple breast cancer families. Cancer Prev Res (Phila) 2011;4:1002-1010.

93. Tryggvadottir L, Vidarsdottir L, Thorgeirsson T, et al. Prostate cancer progression and survival in BRCA2 mutation carriers. J Natl Cancer Inst 2007;99:929-935.

94. Engel C, Loeffler M, Steinke V, et al. Risks of less common cancers in proven mutation carriers with lynch syndrome. J Clin Oncol 2012;30:4409-4415.

95. Haraldsdottir S, Hampel H, Wei L, et al. Prostate cancer incidence in males with Lynch syndrome. Genet Med 2014;16:553-557.

96. Raymond VM, Mukherjee B, Wang F, et al. Elevated risk of prostate cancer among men with Lynch syndrome. J Clin Oncol 2013;31:1713-1718.

97. Ryan S, Jenkins MA, Win AK. Risk of prostate cancer in Lynch syndrome: a systematic review and meta-analysis. Cancer Epidemiol Biomarkers Prev 2014;23:437-449

98. Win AK, Lindor NM, Young JP, et al. Risks of primary extracolonic cancers following colorectal cancer in lynch syndrome. J Natl Cancer Inst 2012;104:1363-1372.

99. Bancroft EK, Page EC, Castro E, et al. Targeted prostate cancer screening in BRCA1 and BRCA2 mutation carriers: results from the initial screening round of the IMPACT study. Eur Urol 2014;66:489-499.

100. Schroder FH, Roobol-Bouts M, Vis AN, et al. Prostate-specific antigenbased early detection of prostate cancer--validation of screening without rectal examination. Urology 2001;57:83-90.

101. Ankerst DP, Hoefler J, Bock S, et al. Prostate Cancer Prevention Trial risk calculator 2.0 for the prediction of low- vs high-grade prostate cancer Urology 2014;83:1362-1367.

102. Nam RK, Kattan MW, Chin JL, et al. Prospective multi-institutional study evaluating the performance of prostate cancer risk calculators. J Clin Oncol 2011;29:2959-2964.

103. Nam RK, Toi A, Klotz LH, et al. Assessing individual risk for prostate cancer. J Clin Oncol 2007;25:3582-3588.

104. Roobol MJ, Steyerberg EW, Kranse R, et al. A risk-based strategy improves prostate-specific antigen-driven detection of prostate cancer. Eur Urol 2010;57:79-85

105. Glass AS, Cary KC, Cooperberg MR. Risk-based prostate cancer screening: who and how? Curr Urol Rep 2013;14:192-198.

106. Prostate Imaging Reporting and Data System (PI-RADS) Version 2. Available at: http://www.acr.org/Quality-Safety/Resources/PIRADS Accessed April 29, 2015.

107. Barentsz JO, Richenberg J, Clements R, et al. ESUR prostate MR guidelines 2012. Eur Radiol 2012;22:746-757.

108. Kuru TH, Roethke MC, Seidenader J, et al. Critical evaluation of magnetic resonance imaging targeted, transrectal ultrasound guided transperineal fusion biopsy for detection of prostate cancer. J Urol 2013;190:1380-1386.

109. Pokorny MR, de Rooij M, Duncan E, et al. Prospective study of diagnostic accuracy comparing prostate cancer detection by transrectal ultrasoundguided biopsy versus magnetic resonance (MR) imaging with subsequent MR-guided biopsy in men without previous prostate biopsies. Eur Urol 2014;66:22-29.

110. Tonttila PP, Lantto J, Paakko E, et al. Prebiopsy multiparametric magnetic resonance imaging for prostate cancer diagnosis in biopsy-naive men with suspected prostate cancer based on elevated prostate-specific antigen values: results from a randomized prospective blinded controlled trial. Eur Urol 2015; pii: S0302-2838(15)00426-1.

111. Siddiqui MM, Rais-Bahrami S, Turkbey B, et al. Comparison of MR/ ultrasound fusion-guided biopsy with ultrasound-guided biopsy for the diagnosis of prostate cancer. JAMA 2015;313:390-397.

112. Oesterling JE, Jacobsen SJ, Chute CG, et al. Serum prostate-specific antigen in a community-based population of healthy men: establishment of age-specific reference ranges. JAMA 1993;270:860-864.

113. Morgan TO, Jacobsen SJ, McCarthy WF, et al. Age-specific reference ranges for prostate-specific antigen in black men. $\mathrm{N}$ Engl J Med 1996;335:304-310. 
114. Oesterling JE, Jacobsen SJ, Klee GG, et al. Free, complexed and total serum prostate specific antigen: the establishment of appropriate reference ranges for their concentrations and ratios. J Urol 1995;154:1090-1095.

115. Moul JW. Targeted screening for prostate cancer in African-American men. Prostate Cancer Prostatic Dis 2000;3:248-255.

116. Carter HB, Pearson JD, Metter EJ, et al. Longitudinal evaluation of prostate-specific antigen levels in men with and without prostate disease. JAMA 1992;267:2215-2220.

117. Carter HB, Ferrucci L, Kettermann A, et al. Detection of life-threatening prostate cancer with prostate-specific antigen velocity during a window of curability. J Natl Cancer Inst 2006;98:1521-1527.

118. D'Amico AV, Chen MH, Roehl KA, Catalona WJ. Preoperative PSA velocity and the risk of death from prostate cancer after radical prostatectomy. N Engl J Med 2004;351:125-135

119. D'Amico AV, Renshaw AA, Sussman B, Chen MH. Pretreatment PSA velocity and risk of death from prostate cancer following external beam radiation therapy. JAMA 2005;294:440-447.

120. Vickers AJ, Till C, Tangen CM, et al. An empirical evaluation of guidelines on prostate-specific antigen velocity in prostate cancer detection. I Natl Cancer Inst 2011;103:462-469.

121. Elshafei A, Li YH, Hatem A, et al. The utility of PSA velocity in prediction of prostate cancer and high grade cancer after an initially negative prostate biopsy. Prostate 2013;73:1796-1802.

122. Wolters $\mathrm{T}$, Roobol MJ, Bangma $\mathrm{CH}$, Schroder FH. Is prostate-specific antigen velocity selective for clinically significant prostate cancer in screening? European Randomized Study of Screening for Prostate Cancer (Rotterdam). Eur Urol 2009;55:385-392.

123. Loeb S, Roehl KA, Helfand BT, et al. Can prostate specific antigen velocity thresholds decrease insignificant prostate cancer detection? J Urol 2010;183:112-116.

124. Eggener SE, Roehl KA, Catalona WJ. Prostatitis confounds the use of PSA velocity for prostate cancer detection [abstract]. Presented at the ASCO Prostate Cancer Symposium; 2006. Abstract 4.

125. Partin AW, Brawer MK, Subong EN, et al. Prospective evaluation of percent free-PSA and complexed-PSA for early detection of prostate cancer. Prostate Cancer Prostatic Dis 1998;1:197-203.

126. Partin AW, Brawer MK, Bartsch G, et al. Complexed prostate specific antigen improves specificity for prostate cancer detection: results of a prospective multicenter clinical trial. J Urol 2003;170:1787-1791.

127. Okihara K, Cheli CD, Partin AW, et al. Comparative analysis of complexed prostate specific antigen, free prostate specific antigen and their ratio in detecting prostate cancer. J Urol 2002;167:2017-2023; discussion 20232024.

128. Horninger W, Cheli CD, Babaian RJ, et al. Complexed prostate-specific antigen for early detection of prostate cancer in men with serum prostatespecific antigen levels of 2 to 4 nanograms per milliliter. Urology 2002;60:31-35

129. Okihara K, Fritsche HA, Ayala A, et al. Can complexed prostate specific antigen and prostatic volume enhance prostate cancer detection in men with total prostate specific antigen between 2.5 and $4.0 \mathrm{ng} . / \mathrm{ml}$. J Urol 2001;165:1930-1936.

130. Babaian RJ, Naya Y, Cheli C, Fritsche HA. The detection and potential economic value of complexed prostate specific antigen as a first line test. J Urol 2006;175:897-901; discussion 901.

131. Veneziano S, Pavlica P, Querze R, et al. Correlation between prostatespecific antigen and prostate volume, evaluated by transrectal ultrasonography: usefulness in diagnosis of prostate cancer. Eur Urol 1990;18:112-116.

132. Benson MC, Whang IS, Pantuck A, et al. Prostate specific antigen density: a means of distinguishing benign prostatic hypertrophy and prostate cancer. J Urol 1992;147:815-816.

133. Lujan M, Paez A, Llanes $L$, et al. Prostate specific antigen density. Is there a role for this parameter when screening for prostate cancer? Prostate Cancer Prostatic Dis 2001;4:146-149.

134. Sozen S, Eskicorapci S, Kupeli B, et al. Complexed prostate specific antigen density is better than the other PSA derivatives for detection of prostate cancer in men with total PSA between 2.5 and $20 \mathrm{ng} / \mathrm{ml}$ : results of a prospective multicenter study. Eur Urol 2005;47:302-307.

135. Veneziano S, Pavlica P, Compagnone G, Martorana G. Usefulness of the (F/T)/PSA density ratio to detect prostate cancer. Urol Int 2005;74:13-18.

136. Aksoy $\mathrm{Y}$, Oral A, Aksoy H, et al. PSA density and PSA transition zone density in the diagnosis of prostate cancer in PSA gray zone cases. Ann Clin Lab Sci 2003;33:320-323.
137. Allan RW, Sanderson H, Epstein JI. Correlation of minute ( $0.5 \mathrm{MM}$ or less) focus of prostate adenocarcinoma on needle biopsy with radical prostatectomy specimen: role of prostate specific antigen density. J Urol 2003;170:370-372.

138. Radwan MH, Yan Y, Luly JR, et al. Prostate-specific antigen density predicts adverse pathology and increased risk of biochemical failure. Urology 2007;69:1121-1127.

139. Catalona WJ, Southwick PC, Slawin KM, et al. Comparison of percent free PSA, PSA density, and age-specific PSA cutoffs for prostate cancer detection and staging. Urology 2000;56:255-260.

140. Gittelman MC, Hertzman B, Bailen J, et al. PCA 3 molecular urine test as a predictor of repeat prostate biopsy outcome in men with previous negative biopsies: a prospective multicenter clinical study. The Journal of urology 2013;190:64-69.

141. Bradley LA, Palomaki GE, Gutman S, et al. Comparative effectiveness review: prostate cancer antigen 3 testing for the diagnosis and management of prostate cancer. J Urol 2013;190:389-398.

142. Auprich M, Bjartell A, Chun FK, et al. Contemporary role of prostate cancer antigen 3 in the management of prostate cancer. European urology 2011;60:1045-1054.

143. Aubin SM, Reid J, Sarno MJ, et al. PCA 3 molecular urine test for predicting repeat prostate biopsy outcome in populations at risk: validation in the placebo arm of the dutasteride REDUCE trial. J Urol 2010;184:1947-1952.

144. Wei JT, Feng Z, Partin AW, et al. Can urinary PCA3 supplement PSA in the early detection of prostate cancer? J Clin Oncol 2014;32:4066-4072.

145. Vickers AJ. Markers for the early detection of prostate cancer: some principles for statistical reporting and interpretation. J Clin Oncol 2014;32:4033-4034.

146. Filella X, Gimenez N. Evaluation of [-2] proPSA and Prostate Health Index (phi) for the detection of prostate cancer: a systematic review and meta-analysis. Clin Chem Lab Med2013;51:729-739.

147. Lazzeri M, Haese A, Abrate A, et al. Clinical performance of serum prostate-specific antigen isoform [-2]proPSA (p2PSA) and its derivatives, $\%$ p2PSA and the prostate health index (PHI), in men with a family history of prostate cancer: results from a multicentre European study, the PROMEtheuS project. BJU Int 2013;112:313-321.

148. Loeb S. Prostate cancer: Prostate Health Index-improving screening in men with family history. Nat Rev Urol 2013;10:497-498.

149. Catalona WJ, Partin AW, Sanda MG, et al. A multicenter study of [-2]proprostate specific antigen combined with prostate specific antigen and free prostate specific antigen for prostate cancer detection in the 2.0 to $10.0 \mathrm{ng} /$ $\mathrm{ml}$ prostate specific antigen range. J Urol 2011;185:1650-1655.

150. Vickers A, Cronin A, Roobol M, et al. Reducing unnecessary biopsy during prostate cancer screening using a four-kallikrein panel: an independent replication. J Clin Oncol 2010;28:2493-2498.

151. Vickers AJ, Gupta A, Savage CJ, et al. A panel of kallikrein marker predicts prostate cancer in a large, population-based cohort followed for 15 years without screening. Cancer Epidemiol Biomarkers Prev 2011;20:255-261.

152. Parekh DJ, Punnen S, Sjoberg DD, et al. A multi-institutional prospective trial in the USA confirms that the 4Kscore accurately identifies men with high-grade prostate cancer. Eur Urol 2014;68:464-470.

153. Bryant RJ, Sjoberg DD, Vickers AJ, et al. Predicting high-grade cancer at ten-core prostate biopsy using four Kallikrein markers measured in blood in the Protec T Study. J Natl Cancer Inst 2015;107.

154. Stewart GD, Van Neste L, Delvenne P, et al. Clinical utility of an epigenetic assay to detect occult prostate cancer in histopathologically negative biopsies: results of the MATLOC study. J Urol 2013;189:1110-1116.

155. Partin AW, Van Neste $L$, Klein EA, et al. Clinical validation of an epigenetic assay to predict negative histopathological results in repeat prostate biopsies. J Urol 2014;192:1081-1087.

156. Presti JC, Jr., O’Dowd GJ, Miller MC, et al. Extended peripheral zone biopsy schemes increase cancer detection rates and minimize variance in prostate specific antigen and age related cancer rates: results of a community multi-practice study. J Urol 2003;169:125-129.

157. Ukimura O, Coleman JA, de la Taille A, et al. Contemporary role of systematic prostate biopsies: indications, techniques, and implications for patient care. Eur Urol 2013;63:214-230.

158. Robertson NL, Emberton M, Moore CM. MRI-targeted prostate biopsy: a review of technique and results. Nat Rev Urol 2013;10:589-597.

159. Maccagnano C, Gallina A, Roscigno M, et al. Prostate saturation biopsy following a first negative biopsy: state of the art. Urol Int 2012;89:126-135.

160. Rastinehad AR, Turkbey B, Salami SS, et al. Improving detection of clinically significant prostate cancer: MRI/TRUS fusion-guided prostate biopsy. J Urol 2014;191:1749-1754. 
161. Puech P, Rouviere O, Renard-Penna R, et al. Prostate cancer diagnosis: multiparametric MR-targeted biopsy with cognitive and transrectal USMR fusion guidance versus systematic biopsy--prospective multicenter study. Radiology 2013;268:461-469.

162. Hoeks CM, Schouten MG, Bomers JG, et al. Three-Tesla magnetic resonance-guided prostate biopsy in men with increased prostate-specific antigen and repeated, negative, random, systematic, transrectal ultrasound biopsies: detection of clinically significant prostate cancers. Eur Urol 2012;62:902-909.

163. Portalez D, Mozer P, Cornud F, et al. Validation of the European Society of Urogenital Radiology scoring system for prostate cancer diagnosis on multiparametric magnetic resonance imaging in a cohort of repeat biopsy patients. Eur Urol 2012;62:986-996.

164. Sonn GA, Chang E, Natarajan S, et al. Value of targeted prostate biopsy using magnetic resonance-ultrasound fusion in men with prior negative biopsy and elevated prostate-specific antigen. Eur Urol 2014;65:809-815.

165. Vourganti S, Rastinehad A, Yerram NK, et al. Multiparametric magnetic resonance imaging and ultrasound fusion biopsy detect prostate cancer in patients with prior negative transrectal ultrasound biopsies. J Urol 2012;188:2152-2157.

166. Roethke M, Anastasiadis AG, Lichy M, et al. MRI-guided prostate biopsy detects clinically significant cancer: analysis of a cohort of 100 patients after previous negative TRUS biopsy. World J Urol 2012;30:213-218.

167. Sciarra A, Panebianco V, Ciccariello $M$, et al. Value of magnetic resonance spectroscopy imaging and dynamic contrast-enhanced imaging for detecting prostate cancer foci in men with prior negative biopsy. Clin Cancer Res 2010;16:1875-1883.

168. Anastasiadis AG, Lichy MP, Nagele U, et al. MRI-guided biopsy of the prostate increases diagnostic performance in men with elevated or increasing PSA levels after previous negative TRUS biopsies. Eur Urol 2006;50:738-748; discussion 748-739.

169. Rais-Bahrami S, Siddiqui MM, Turkbey B, et al. Utility of multiparametric magnetic resonance imaging suspicion levels for detecting prostate cancer. J Urol 2013;190:1721-1727.

170. Nelson AW, Harvey RC, Parker RA, et al. Repeat prostate biopsy strategies after initial negative biopsy: meta-regression comparing cancer detection of transperineal, transrectal saturation and MRI guided biopsy. PLoS One 2013;8:e57480.

171. Abdollah F, Novara G, Briganti A, et al. Trans-rectal versus trans-perineal saturation rebiopsy of the prostate: is there a difference in cancer detection rate? Urology 2011;77:921-925.

172. Acher P, Dooldeniya M. Prostate biopsy: will transperineal replace transrectal? BJU Int 2013;112:533-534.

173. Grummet JP, Weerakoon M, Huang S, et al. Sepsis and 'superbugs': should we favour the transperineal over the transrectal approach for prostate biopsy? BJU Int 2014;114:384-388.

174. Pepe $\mathrm{P}$, Aragona F. Morbidity after transperineal prostate biopsy in 3000 patients undergoing 12 vs 18 vs more than 24 needle cores. Urology 2013;81:1142-1146.

175. Vyas $L$, Acher $P$, Challacombe $B$, et al. Indications, results and safety profile of transperineal sector biopsies of the prostate: a single centre experience of 634 cases. BJU Int 2014;114:32-37.

176. Murphy DG, Weerakoon M, Grummet J. Is zero sepsis alone enough to justify transperineal prostate biopsy? BJU Int 2014;114:3-4.

177. Taira AV, Merrick GS, Galbreath RW, et al. Performance of transperineal template-guided mapping biopsy in detecting prostate cancer in the initial and repeat biopsy setting. Prostate Cancer Prostatic Dis 2010;13:71-77.

178. Merrick GS, Gutman S, Andreini H, et al. Prostate cancer distribution in patients diagnosed by transperineal template-guided saturation biopsy. Eur Urol 2007;52:715-723.

179. Walz J, Graefen M, Chun FK, et al. High incidence of prostate cancer detected by saturation biopsy after previous negative biopsy series. Eur Urol 2006;50:498-505.

180. Zaytoun OM, Moussa AS, Gao T, et al. Office based transrectal saturation biopsy improves prostate cancer detection compared to extended biopsy in the repeat biopsy population. J Urol 2011;186:850-854.

181. Liss MA. Infection: prostate biopsy-infection and prior fluoroquinolone exposure. Nat Rev Urol 2011;8:592-594.

182. Djavan B, Waldert M, Zlotta A, et al. Safety and morbidity of first and repeat transrectal ultrasound guided prostate needle biopsies: results of a prospective European prostate cancer detection study. J Urol 2001;166:856-860.

183. Loeb S, Vellekoop A, Ahmed HU, et al. Systematic review of complications of prostate biopsy. Eur Urol 2013;64:876-892.

184. Loeb S, Carter HB, Berndt SI, et al. Complications after prostate biopsy: data from SEER-Medicare. J Urol 2011;186:1830-1834.

185. Nam RK, Saskin R, Lee $Y$, et al. Increasing hospital admission rates for urological complications after transrectal ultrasound guided prostate biopsy. J Urol 2010;183:963-968.

186. Pinsky PF, Parnes HL, Andriole G. Mortality and complications after prostate biopsy in the Prostate, Lung, Colorectal and Ovarian Cance Screening (PLCO) trial. BJU Int 2014;113:254-259.

187. Feliciano J, Teper E, Ferrandino $M$, et al. The incidence of fluoroquinolone resistant infections after prostate biopsy--are fluoroquinolones still effective prophylaxis? J Urol 2008;179:952-955; discussion 955

188. Zaytoun OM, Vargo EH, Rajan R, et al. Emergence of fluoroquinoloneresistant Escherichia coli as cause of postprostate biopsy infection: implications for prophylaxis and treatment. Urology 2011;77:1035-1041.

189. Akduman B, Akduman $\mathrm{D}$, Tokgoz $\mathrm{H}$, et al. Long-term fluoroquinolone use before the prostate biopsy may increase the risk of sepsis caused by resistant microorganisms. Urology 2011;78:250-255.

190. Mosharafa AA, Torky MH, El Said WM, Meshref A. Rising incidence of acute prostatitis following prostate biopsy: fluoroquinolone resistance and exposure is a significant risk factor. Urology 2011;78:511-514.

191. Liss MA, Chang $A$, Santos $R$, et al. Prevalence and significance of fluoroquinolone resistant Escherichia coli in patients undergoing transrectal ultrasound guided prostate needle biopsy. J Urol 2011;185:1283-1288.

192. Collins GN, Lloyd SN, Hehir M, McKelvie GB. Multiple transrectal ultrasound-guided prostatic biopsies--true morbidity and patient acceptance. Br J Urol 1993;71:460-463.

193. Stirling BN, Shockley KF, Carothers GG, Maatman TJ. Comparison of local anesthesia techniques during transrectal ultrasound-guided biopsies. Urology 2002;60:89-92.

194. Hergan L, Kashefi C, Parsons JK. Local anesthetic reduces pain associated with transrectal ultrasound-guided prostate biopsy: a meta-analysis. Urology 2007;69:520-525.

195. Leibovici D, Zisman A, Siegel YI, et al. Local anesthesia for prostate biopsy by periprostatic lidocaine injection: a double-blind placebo controlled study. J Urol 2002;167:563-565.

196. Schröder FH, Roobol MJ. PSA Screening Decision-Making Aid For Patients, General Practitioners and Urologists: Societe Internationale D'Urologie; 2014. Available at: http://www.siu-urology.org/themes/web/ assets/files/society/psa_testing_brochure.pdf. Accessed November 17, 2015.

197. Bostwick DG, Cheng L. Precursors of prostate cancer. Histopathology 2012;60:4-27.

198. Herawi M, Kahane H, Cavallo C, Epstein JI. Risk of prostate cancer on first re-biopsy within 1 year following a diagnosis of high grade prostatic intraepithelial neoplasia is related to the number of cores sampled. J Urol 2006;175:121-124.

199. O’Dowd G J, Miller MC, Orozco R, Veltri RW. Analysis of repeated biopsy results within 1 year after a noncancer diagnosis. Urology 2000;55:553559.

200. Taneja SS, Morton R, Barnette G, et al. Prostate cancer diagnosis among men with isolated high-grade intraepithelial neoplasia enrolled onto a 3 -year prospective phase III clinical trial of oral toremifene. J Clin Oncol 2013;31:523-529.

201. Thompson IM, Jr., Leach R. Prostate cancer and prostatic intraepithelial neoplasia: true, true, and unrelated? J Clin Oncol 2013;31:515-516.

202. Lefkowitz GK, Taneja SS, Brown J, et al. Followup interval prostate biopsy 3 years after diagnosis of high grade prostatic intraepithelial neoplasia is associated with high likelihood of prostate cancer, independent of change in prostate specific antigen levels. J Urol 2002;168:1415-1418.

203. Merrimen JL, Jones G, Srigley JR. Is high grade prostatic intraepithelial neoplasia still a risk factor for adenocarcinoma in the era of extended biopsy sampling? Pathology 2010;42:325-329.

204. Chan TY, Epstein JI. Follow-up of atypical prostate needle biopsies suspicious for cancer. Urology 1999;53:351-355.

205. Mian BM, Naya Y, Okihara K, et al. Predictors of cancer in repeat extended multisite prostate biopsy in men with previous negative extended multisite biopsy. Urology 2002;60:836-840. 
Prostate Cancer Early Detection, Version 2.2015

\section{Individual Disclosures of the NCCN Merkel Cell Carcinoma Panel}

\begin{tabular}{|c|c|c|c|c|}
\hline Panel Member & $\begin{array}{l}\text { Clinical Research } \\
\text { Support/Data Safety } \\
\text { Monitoring Board }\end{array}$ & $\begin{array}{l}\text { Scientific Advisory Boards, } \\
\text { Consultant, or Expert } \\
\text { Witness }\end{array}$ & $\begin{array}{l}\text { Promotional Advisory Boards, } \\
\text { Consultant, or Speakers Bureau }\end{array}$ & $\begin{array}{l}\text { Date } \\
\text { Completed }\end{array}$ \\
\hline Gerald Andriole, MD & None & None & $\begin{array}{l}\text { Augmenix, Inc.; Bayer } \\
\text { HealthCare; Genomic Health, Inc.; } \\
\text { GlaxoSmithKline; Medivation, } \\
\text { Inc.; and Myriad Genetic } \\
\text { Laboratories, Inc. }\end{array}$ & $9 / 08 / 14$ \\
\hline Robert R. Bahnson, MD & None & Various Law Firms & None & $6 / 16 / 15$ \\
\hline Daniel A. Barocas, MD, MPH & AHRQ; and PCORI & $\begin{array}{l}\text { Astellas US LLC; Janssen } \\
\text { Pharmaceuticals, Inc.; and } \\
\text { MDxHealth }\end{array}$ & None & NEEDED \\
\hline Peter R. Carroll, MD, MPH & $\begin{array}{l}\text { Department of } \\
\text { Defense; Genomic } \\
\text { Health, Inc.; Myriad } \\
\text { Genetic Laboratories, } \\
\text { Inc.; and NCl }\end{array}$ & None & None & $10 / 06 / 15$ \\
\hline Erik P. Castle, MD & None & Bayer HealthCare & None & $10 / 05 / 15$ \\
\hline William J. Catalona, MDa & $\begin{array}{l}\text { Beckman Coulter, Inc.; } \\
\text { deCODE genetics; and } \\
\text { Ohmx Corporation }\end{array}$ & $\begin{array}{l}\text { Beckman Coulter, Inc; } \\
\text { deCODE genetics; and } \\
\text { Ohmx Corporation }\end{array}$ & $\begin{array}{l}\text { Beckman Coulter, Inc.; and Ohmx } \\
\text { Corporation }\end{array}$ & $10 / 14 / 15$ \\
\hline Douglas M. Dahl, MD & None & None & None & $10 / 03 / 15$ \\
\hline John W. Davis, MD & $\begin{array}{l}\text { GenomeDx } \\
\text { Biosciences Inc.; } \\
\text { Gen-Probe; Jannsen } \\
\text { Pharmaceutica } \\
\text { Products, LP; MiMedx; } \\
\text { and Myriad Genetic } \\
\text { Laboratories, Inc. }\end{array}$ & $\begin{array}{l}\text { Astellas US LLC/ } \\
\text { Medivation, Inc. }\end{array}$ & Springer, US & $8 / 26 / 15$ \\
\hline Jonathan I. Epstein, MD & None & None & $\begin{array}{l}\text { Aperio; Dianon Pathology; and } \\
\text { Metamark Genetics, Inc. }\end{array}$ & $10 / 07 / 15$ \\
\hline Ruth B. Etzioni, PhD & None & None & None & $10 / 05 / 15$ \\
\hline Thomas Farrington, BSEE & None & None & None & $6 / 15 / 15$ \\
\hline George P. Hemstreet III, MD, PhD & None & None & None & $10 / 08 / 15$ \\
\hline Mark H. Kawachi, MD & None & None & None & $8 / 28 / 15$ \\
\hline Paul H. Lange, MD & None & None & None & $8 / 13 / 15$ \\
\hline Kevin R. Loughlin, MD & None & None & None & $10 / 09 / 15$ \\
\hline William Lowrance, MD, MPH & $\begin{array}{l}\text { Argos Therapeutics, } \\
\text { Inc.; GenomeDx } \\
\text { Biosciences Inc.; } \\
\text { Myriad Genetic } \\
\text { Laboratories, Inc.; } \\
\text { and NCl }\end{array}$ & MDxHealth & None & $10 / 01 / 15$ \\
\hline Paul Maroni, MD & None & None & None & $8 / 07 / 15$ \\
\hline James Mohler, MDa & $\mathrm{NCl}$ & Genomic Health, Inc. & None & $8 / 18 / 15$ \\
\hline Todd M. Morgan, MD & $\begin{array}{l}\text { MDxHealth; and } \\
\text { Myriad Genetic } \\
\text { Laboratories, Inc. }\end{array}$ & $\begin{array}{l}\text { MDxHealth; and Myriad } \\
\text { Genetic Laboratories, Inc. }\end{array}$ & None & $8 / 06 / 15$ \\
\hline Robert B. Nadler, MD & None & None & None & $10 / 05 / 15$ \\
\hline J. Kellogg Parsons, MD, MHS & $\begin{array}{l}\mathrm{NCl} \text {; and Watson } \\
\text { Pharmaceuticals, Inc. }\end{array}$ & Legal firms & None & $9 / 26 / 15$ \\
\hline Michael Poch, MD & None & None & None & $10 / 07 / 15$ \\
\hline Chuck Scales, MD & None & None & None & $10 / 09 / 15$ \\
\hline Terrence M. Shaneyfelt, MD, MPH & None & None & None & $8 / 13 / 15$ \\
\hline Marc C. Smaldone, MD, MSHP & None & None & None & $10 / 06 / 15$ \\
\hline Geoffrey Sonn, MD & None & None & None & $10 / 08 / 15$ \\
\hline Preston Sprenkle, MD & None & None & None & 9/30/15 \\
\hline Andrew J. Vickers, $\mathrm{PhD}^{\mathrm{a}}$ & $\mathrm{NCl}$ & $\begin{array}{l}\text { COONEY, SCULLY AND } \\
\text { DOWLING; and OPKO } \\
\text { Health, Inc. }\end{array}$ & GenomeDx Biosciences Inc. & $8 / 17 / 15$ \\
\hline Robert Wake, MD & None & None & None & $9 / 30 / 15$ \\
\hline
\end{tabular}

aThe following individuals have disclosed that they have an Employment/Governing Board, Patent, Equity, or Royalty conflict:

William Catalona, MD: Ohmx Corporation

James Mohler, MD: Androbiosys, Inc.

Andrew Vickers, PhDa: Arctic Partners, and OPKO Health, Inc.

The NCCN Guidelines staff have no conflicts to disclose. 